\title{
Rapid Evaluation of Ion Thruster Lifetime Using Optical Emission Spectroscopy
}

Brian A. Rock

Arizona State University

Tempe, Arizona

Maris A. Mantanieks

Lewis Research Center

Cleveland, Ohio

and

Michael L. Parsons

hition

Arizona State University

Tempe, Arizona

Iniv 6 yes

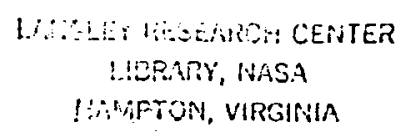

Prepared for the

18th International Electric Propulsion Conference cosponsored by the AIAA, JSASS, and DGLR

Alexandria, Virginia, September 30-October 2, 1985 
RAPID EVALUATION OF ION THRUSTER LIFETIME USING

OPTICAL EMISSION SPECTROSCOPY

Brian A. Rock

Arizona State University

Tempe, Arizona

and

Maris A. Mantenieks

National Aeronautics and Space Administration

Lewis Research Center

Cleveland, Ohio 44135

and

Michael L. Parsons

Arizona State University

Tempe, Arizona

\section{SUMMARY}

A major life-limiting phenomenon of electric thrusters is the sputter erosion of discharge chamber components. Thrusters for space propulsion are required to operate for extended periods of time, usually in excess of.

$10000 \mathrm{hr}$. Lengthy and very costly life-tests in high-vacuum facilities have been required in the past to determine the erosion rates of thruster components. It is, therefore, highly desirable to develop alternative methods for determining erosion rates which can be performed in relatively short periods of time at considerably lower costs.

This paper presents an attempt to relate optical emission intensity from an ion bombarded surface (screen grid) to the sputtering rate of that surface. The model used a kinetic steady-state (KSS) approach, balancing the rates of population and depopulation of ten low-lying excited states of the sputtered molybdenum atom (MOI) with those of the ground state to relate the spectral intensities of the various transitions of the MoI to the population densities. Once this is accomplished, the population density can be related to the sputtering rate of the target. Radiative and collisional modes of excitation and decay were considered. Since actual data has not been published for MoI excitation and decay rate constants, semiempirical equations were used.

The calculated sputtering rate and intensity was compared to the measured emission intensity of the excited sputtered MoI and sputtering rates of the 8and $30-\mathrm{cm}$ ion thrusters using semiempirical equations for the electron density, temperature of the discharge plasma and sputtering yields of a $\mathrm{Hg} \rightarrow$ Mo system.

\section{INTRODUCTION}

A major life-limiting phenomenon of electric thrusters is the sputter erosion of discharge chamber components. Thrusters for space propulsion are 
required to operate for extended periods of time, usually in excess of $10000 \mathrm{hr}$. Lengthy and very costly life tests in high vacuum facilities have been required in the past to determine the erosion rates of thruster components. Alternative methods for determining erosion rates which can be performed in relatively short periods of time and at considerably lower costs are, therefore, highly desirable.

This paper presents an attempt to relate the optical emission intensity from an ion bombarded surface (screen grid) to the sputtering rate of that surface. Several methods have been tried and tested. One consists of attaching a "badge" consisting of alternate layers of very thin metal layers to the sputtered surface (ref. 1). Such a technique has not always yielded results which agreed with long term life tests (ref. 2). Another technique would be to apply absorption spectroscopy to the life-time determination. Emission spectroscopy was applied by Wehner about $20 \mathrm{yr}$ ago in an attempt to measure relative sputtering rates of various target materials by inert gas ions at low energies (ref. 3). The ion thruster plasma, however, represents a much more complicated system than the experimental arrangement of Wehner.

First, the thruster discharge plasma was characterized in regard to the equilibrium conditions and optical depth of the plasma. The lack of thermal equilibrium complicates the understanding of the plasma as well as the formulation of the model. The determination of the optical depth of the plasma determines if any radiation is absorbed within the plasma.

This work uses a steady state kinetic model to infer the population dynam. ics of the sputtered molybdenum "impurity" atoms in an ion thruster plasma. This approach requires a knowledge of basic plasma parameters as well as spectroscopic emission data of the important molybdenum atomic transitions. A total molybdenum atom population can be found, which can be related to the sputtering rate of the molybdenum surface, using known relationships. The model formulated was compared to measured relative spectroscopic intensities from an 8 - and $30-\mathrm{cm} \mathrm{Hg}$ ion thrusters. For a more complete treatment of this study see reference 3 .

\section{CHARACTERIZATION OF ION THRUSTER PLASMAS}

The parameters, which are of primary importance in characterizing the properties of a plasma are its electron temperature and electron density. In many plasmas, the energy distribution of the electrons is sufficiently close to a Maxwellian form so that a meaningful temperature can be assigned to the electrons; this temperature may not be equivalent to the temperature of either the atoms or the ions in the plasma, particularly in some laboratory plasmas (ref. 4). The range of electron densities in plasmas varies from below 104 to above 1017 electrons/cc. Electron temperatures, typically expressed as energies, range from 0.01 to over $100000 \mathrm{eV}$. Such a wide variety in these basic parameters implies a wide diversity of plasma characteristics. For the purpose of characterizing plasma behavior the collisional-radiative model covers virtually all known plasmas. There exist special cases for which simplifications in the required calculations can be made. Two of these special cases are the corona and the local thermodynamic equilibrium models.

Additionally, the optical thickness of a plasma must be considered. An optically thin plasma is easier to treat for both the collisional-radiative 
and the corona models. Both of these models are based on the assumption that the plasma is optically thin, particularly with respect to its resonance lines. Where this assumption is not valid, corrections must be added to account for the plasma's absorption (ref. 5).

\section{The Local Theromodynamic Equilibrium Model}

The simplest of the models from a calculational point of view is the local thermodynamic equilibrium (LTE) model. The LTE model assumes that collisional processes are dominant in the plasma and that the particle collision rates are high enough so that the system can instantaneously adjust to any change in plasma conditions. A system in local thermodynamic equilibrium is governed by the same mathematical expressions as systems which are in total thermodynamic equilibrium although, an LTE system does not meet all of the criteria required of a system in total thermodynamic equilibrium. In an LTE system, population densities need not be equal at different points in the plasma. The plasma also need not have a single overall temperature. At any point in the plasma, a local temperature is meaningful and the density and chemical composition of the plasma at this point, in conjunction with this temperature, can be used to define the population of the various energy levels in that region by means of a thermodynamic equilibrium approximation.

If collisional processes are to dominate radiative ones in a plasma, sufficient number density must be present so that frequent collisional excitation and decay can occur. If an optically thin plasma is assumed, then radiative excitation can be ignored. The criteria for the existence of local thermodynamic equilibrium would then be that the collisional decay rate must be significantly greater than the radiative decay rate.

A wide variety of possible colliding species exist in an ion thruster plasma. It should be noted that most of the species are present to a much smaller extent than the two major components of the plasma, propellant atoms and electrons. These two species are present in concentrations which are usually within an order of magnitude of each other and which exceed by at least two orders of magnitude the populations of any of the other species. Electrons are much more efficient in producing excitation and decay than are atoms, for reasons to be discussed in a later section. Therefore, it is reasonable to assume that collisional effects on excitation and decay are solely governed by collisions between plasma electrons and plasma atoms. It is for this reason that electron density and energy are important plasma parameters.

Sputtered molybdenum atoms in low-lying excited states, are also of importance in the determination of both the rate of collisional decay and in the rate of radiative decay; both rates are proportional to the population densities of the excited molybdenum atoms. The collisional decay rate is the product of the electron density of the plasma, the density of molybdenum atoms in the excited state being considered and a collisional deexcitation rate constant, yielding a transition rate per unit time and unit volume. The corresponding radiative decay rate is the product of the density of the excited state of the molybdenum atom and its Einstein transition probability. A criterion of ten used to determine the validity of the LTE assumption is that, for LTE to 
exist, the collisional decay rate must exceed the radiative decay rate by at least a factor of 10:

$$
n_{e} n_{j} R_{C D} \geq 10\left(n_{j} \sum_{i<j} A_{j i}\right)
$$

or, equivalent to this,

$$
\kappa_{\mathrm{CD}} \geq 10 \kappa_{\mathrm{RD}}
$$

where $n_{e}$ is the electron density in electrons/cc, $n_{j}$. is the density of the $j$ (upper) state of the molybdenum atom, in atoms/cc, $R_{C D}$ is the collisional deexcitation rate constant, in transitions $5^{-1}$ electron-1 atom -1 , and $A_{j i}$ is the Einstein transition probability, in transitions atom-1 $\mathrm{s}^{-1}$ (often expressed as $s^{-1}$ ). The sum of these transition probabilities below state $j$ represents the radiative decay of state $j$ to all lower states. When nonresonance transitions are ignored, this summation reduces to a single transition probability $A_{j i}$, where the state $i$ is taken to be the ground state of the atom. KCD represents the rate of collisional decay and KRD represents the rate of radiative decay, both in units of transition/s. When the above inequality is satisfied, a local thermodynamic equilibrium approach is justified.

It can be seen from equation (1), that plasmas with very high electron densities are more likely to be in local thermodynamic equilibrium than low electron density plasmas (ref. 5).

\section{The Corona Model}

Another important model of plasma behavior is the corona model. This model was proposed to explain some of the features of the solar corona; it is equally applicable to low-density laboratory plasmas.

The corona model is based on the fact that, in a low-density plasma, radiative decay will predominate collisional decay. This occurs because a low-density plasma cannot support a rate of collision high enough to compete with radiative decay. The assumption of optical transparency can usually be made for the corona model. The criterion for coronal equilibrium is therefore that the collisional excitation rate must balance the radiative decay rate. Equation (2) states this mathematically:

$$
n_{e} n_{i} R_{C E}=n_{j} \sum_{\substack{i \\ i<j}} A_{j i}
$$

or, equivalentiy,

$$
{ }^{\kappa_{C E}}=\kappa_{\mathrm{RD}}
$$


where $n_{1}$ is the density of the molybdenum atom lower state in atom/s, $R_{C E}$ is the collisional excitation rate constant, in transitions $s^{-1}$ electron- $T$ atom $^{-1}$, and ${ }^{K} C E$ represents the rate of collisional excitation. Other terms are as defined in equation (1).

The assumptions of the coronal model break down as the density of a plasma goes up. When collisional decay becomes significant the balance between colisional excitation and radiative decay is lost. A criterion similar to that given to evaluate local thermodynamic equilibrium can be developed for the coronal model. When the collisional decay rate exceeds 10 percent of the radiative decay rate, the corona model becomes inappropriate.

$$
n_{j} \sum_{\substack{i \\ i<j}} A_{j i} \geq 10\left(n_{e} n_{j} R_{C D}\right)
$$

or, equivalently,

$$
\kappa_{\mathrm{RD}} \geq 10 \kappa_{\mathrm{CD}}
$$

When the above inequality is satisfied, a corona equilibrium approximation is justified. Corona equilibrium is favored by low electron densities (ref. 24). As will be shown later, over the range of electron temperatures and densities of an ion thruster considered, radiative decay always exceeds collisional decay. This implies that the corona model may also be appropriate for an ion thruster.

\section{The Collisional-Radiative Model}

For those situations where neither the local thermodynamic equilibrium model or the corona model are appropriate, the collisional-radiative model can be used. This model accounts for the effects of both collisional and radiative decay on the upper levels of the system. To some degree, it bridges the gap between the LTE model, where collisional decay dominates the decay process and the corona model, where radiative decay is predominant from all excited states. The collisional-radiative model is appropriate for those plasmas which have an intermediate electron density, such that neither radiative decay, nor collisional decay can be neglected (ref. 5). This method will be applied herein.

\section{Optical Thickness, Absorptivity}

It was stated earlier that the opacity of a plasma to its various spectral lines could complicate the implementation of a plasma model. In particular, radiation trapping in the corona and collisional-radiative models can increase the calculational overhead considerably. Some method is needed to quantitatively evaluate the optical thickness of an ion thruster plasma at any given frequency or wavelength of radiation. A commonly used approximation is the method described by Griem (ref. 6). This method makes several assumptions about broadening mechanisms in plasmas as well as values for "typical" oscillator strengths in plasmas, which are not appropriate to the ion thruster system. An alternate method of evaluating optical thickness, detailed by Alkemade (ref. 7) and without the limiting assumptions of Griem will be discussed. 
For a uniform plasma, a quantity called the absorptivity can be defined as

$$
L\left(v_{0}\right)=2.65 \times 10^{-2} n_{i} f_{i j} / \Delta v_{e f f}
$$

where $L\left(v_{0}\right)$ is the absorptivity of the line at line center, in $\mathrm{cm}^{-1}, \mathrm{n}_{1}$ is the number density of the lower state of the atom in atoms/cc, $f$ ij is the absorption oscillator strength for the transition under consideration and $\Delta v_{\text {eff }}$ is the Doppler width at half-intensity in centimeter (ref. 7). Besides allowing pertinent oscillator strengths to be used, this approach permits a choice of methods to estimate the spectral line broadening parameter, $\Delta v e f f$. In the case of the ion thruster, Doppler broadening will be present, but in a nonstandard form. Normal Doppler broadening can be estimated using equation ( $5 \mathrm{a})$,

$$
\delta v_{D}=2\left(v_{0} / c\right) \sqrt{(2 \ln 2) \mathrm{kT} / \mathrm{m}}
$$

where $\delta v_{0}$ is the normal Doppler spectral halfwidth in $5^{-1}, k$ is the Boltzmann constant, $T$ is the atom temperature in $K, m$ is the mass of the species of interest, in $g, v_{0}$ is the frequency at the line center in $5^{-1}$ and $c$ is the speed of light in $\mathrm{cm} / \mathrm{sec}$ (ref. 8 ).

Normally, the result from equation ( $5 a$ ) would be used in equation (4) to calculate absorptivity. However, Doppler broadening is expected to be atypical for molybdenum atoms in an ion thruster (ref. 3). The following equation approximates the effect of this difference.

$$
\Delta v_{\mathrm{eff}} \approx \frac{1}{2} \delta v_{\mathrm{D}}
$$

The result from equation (5b) is used in equation (4), yielding the values shown in table I.

To evaluate optical thickness using absorptivity, the absorptivity is multiplied by $\ell$, the path length of the plasma along the optical axis. If this quantity is significantly below one, the plasma can be considered opticaliy thin. The recommended upper limit for $L\left(v_{0}\right) \ell$ is between 0.1 and 0.2 . This allows for the error present in the values used for these calculations (ref. 9). Typical values for $\ell$ in the fon thruster are on the order of $10.0 \mathrm{~cm}$. The data in table I shows that, for molybdenum kinetic energies above $1.0 \mathrm{eV}$, the plasma is transparent to the radiation of the ten transitions dealt with by this model. Evidence will be presented later showing that molybdenum energies will exceed this $1.0 \mathrm{eV} 1$ imit and therefore, the plasma can be considered optically thin.

\section{FORMULATION OF KINETIC STEADY-STATE (KSS) MODEL}

The goal of this work is to relate measured intensities of molybdenum spectral lines, to the rate of sputter damage to the molybdenum screen grid of the ion thruster. It is desirable to keep the model as simple as possible, to avoid the need for large amounts of computer calculations. It is also important to keep the model as general as possible, to allow it to be adapted easily for use on other types of electron bombardment ion thrusters, with different propellants, such as xenon, or with different magnetic field configurations. 
The model assumes that the molybdenum ionization rate is so small that it can be neglected. A number of molybdenum atom transitions have been seen in the spectrum obtained from a typical $30-\mathrm{cm}$ thruster. The inclusion of all these transitions is not necessary if the ground state of the molybdenum atom predominates. If more than 90 percent of the molybdenum atoms are in the ground state, the use of a subset of the observed molybdenum transitions should be quite satisfactory.

The model considers the molybdenum ground state and ten low-lying excited states, which are known to have resonance transitions in flames (ref. 11). Only resonance transitions are considered herein. This is done for a number of reasons. The resonance transitions should be significantly more intense than the nonresonance transitions in a relatively low temperature plasma because of the much lower population densities of the excited states, which are the lower states in all nonresonance transitions. Spectroscopic data, such as oscillator strengths and Einstein transition probabilities, for molybdenum atom nonresonance transitions tend to be either of poor quality or unknown (ref. 12). In addition, most of the nonresonance transitions in the eleven state system under consideration will be in the IR region, where accurate intensity measurements are very difficult. For these reasons, nonresonance transitions were omitted from the model.

Two major steps are required to achieve the goal of relating the observed intensity of molybdenum atom transitions to the screen grid sputtering rate. The first step is to relate the spectral intensities of the various transitions of the molybdenum atom to the population densities of the various states of the atom. The second step is to relate this population density data to the screen grid sputter rate.

\section{Steady-State Theory}

The task of calculating the population densities of the various energy levels of a species is relatively easy for systems which are in thermodynamic equilibrium or which satisfy the criteria for local thermodynamic equilibrium. Such a solution relies on the fact that the level populations of a system in or near complete thermodynamic equilibrium behave in a statistically predictable manner, depending only on the temperature of the system, the statistical weights of the levels and the energy differences between these levels. All the particles in a system which are in complete thermodynamic equilibrium share a common temperature, that is, each of the species in the system has a Boltzmann distribution of particle energies which corresponds to one common temperature (ref. 13). Systems which are in local thermodynamic equilibrium share a common temperature in a given region of the plasma; a different region of the plasma may have a different characteristic temperature, but all the particles in that region share that same temperature (ref. 5). Systems which are not near thermodynamic equilibrium are more complicated to treat since they do not behave in the normal statistically predictable manner. For these systems, individual rates for each of the processes occurring in the plasma must be considered (ref. 14). Such rates have not, in general, been measured for most species; usually empirical or semiempirical data is used to estimate the rates of these processes. 
A system such as the ion thruster plasma, governed by a number of processes, should eventually reach a point where the rates of all processes which populate any given level will be balanced by the rates of all processes which depopulate that level. When such a situation occurs, the population of each level is in a steady state condition. As long as no parameter important to any of the processes changes, the population of each level will remain constant. The steady-state approximation allows a system of rate equations to be established. When this system is solved, values for the level populations are generated and in theory, the first major step toward the stated goal of this work is achieved (ref. 15).

\section{Excitation-Decay Rate Constants}

A number of simplifying assumptions were made previously about the nature of an ion thruster plasma. One of these assumptions is that, since molybdenum ion 1 ines have not been observed in ion thruster spectra, ionization can be considered negligible. In such a case, only atomic excitation and deexcitation processes need to be considered. This eliminates from consideration the large numbers of interactions in which ions can be involved in a plasma dis. charge (ref. 16). This leaves two predominant modes of excitation and decay.

Excitation

1. Radiative excitation

2. Collistonal excitation

\section{Decay \\ 1. Radiative decay \\ 2. Collisional decay}

Radiative excitation occurs when a photon is absorbed by an atom of one electronic energy state, yielding an atom at a higher energy state. This process can occur in plasmas and flames with a very high spectral radiation density, such as those which are optically dense or which are 111 uminated by an external light source. Photons which are absorbed by an atom must be very close in energy to the energy required for one of the electron transitions in the atom. A plasma in which photon absorption is occurring will often be optically transparent over most of its spectrum, but in the vicinity of some of its resonance lines, it can be optically thick (ref. 17). Any assumptions of optical transparency should be checked using the methods detalled previously. Results from table I show that the fon thruster plasma is optically transparent to all the molybdenum lines used in this study. It should be noted that the plasma will appear optically thick to the mercury resonance line listed in table I. Since mercury atom intensities do not enter into the mode1, this result does not cause a problem. This value for mercury was included in the table only for comparison. Since the molybdenum atom resonance lines under consideration satisfy the criteria for determining optical transparency by a sufficient margin, radiative excitation should be negligible.

In light of the previous argument against radiative excitation, collisional excitation would appear to be the only excitation mechanism of importance in the main discharge plasma. The various species with which a molybdenum atom may collide were briefly considered previously. Such a collision might involve atoms, ions or electrons. The atomic species present in the thruster are mercury, molybdenum and contaminant atoms. Mercury ions will 
also be present, at a density roughly one to two orders of magnitude less than mercury atoms (ref. 18). Most of these ions will be singly ionized, with a sma11, but significant number of them being doubly ionized. There may be also trace amounts of molybdenum and contaminant ions in the plasma; such species should be present in negligible amounts, compared to mercury ions. Electrons are also present in the discharge; they should be present in the plasma in numbers roughly equivalent to the population density of mercury ions in the plasma (ref. 21). A list of these species, in descending order of their expected population density is given here:

$\mathrm{Hg}$ atoms, electrons $>\mathrm{Hg}$ ions $>$ Mo atoms > contaminant atoms $>$ Mo and contaminant ions.

It is unlikely that any species less common that mercury ions will cause significant collisional excitation. The molybdenum atom number density is expected to be between three and five orders of magnitude less than mercury atoms (ref. 19). In general, atom-atom and atom-ion collisions are not very effective in exciting electronic transitions. Atomic excitation by collision is best thought of in terms of a collision with one of its bound electrons. Energy transfer between particles of such widely differing masses is very inefficient. Transfer of the proper quantity of energy is very unlikely (ref. 20).

As any molybdenum atom which does not collide with a mercury atom (ignoring the other far less populous atoms and fons) will collide with a thruster surface and stick, it appears that not only will atom-atom (or atom-ion) collisions not be very productive in producing excitation, they will also not be particularly common.

Similar reasoning can be applied to electron-atom collisions to show that these collisions should be efficient in producing excitation. A collision of a free electron with a bound electron can result in the transfer of a large fraction of the energy of the free electron to the bound electron (ref. 21 ). The Maxwellian population of electrons have an energy on the order of several electron volts. Since the energy differences between the levels being considered in this model are also several electron volts, there will be a relatively large number of electrons of the proper energy available to excite such transitions. Electron-atom collisions are therefore, considered to be the only important source of excitation of molybdenum atoms in the plasma. The radiative decay rate is dependent only on the Einstein transition probability, $A_{j i}$, and the population of the upper state of the atom (ref. 15).

Collisional decay is the inverse process of collisional excitation. The same reasons which were used to justify the exclusive importance of electronatom collisional excitation apply to collisional decay. Efficient energy transfer and relatively high electron densities make electrons the only collision partners capable of causing significant decay of excited states. Collisional decay might be expected to play a lesser role than radiational decay in many situations; the low number density of the excited states gives the electrons less opportunity to exchange energy in collisions. This is especially true if the electron density of the plasma is relatively low.

Since actual data has not been published for molybdenum atom excitation rate constants, semiempirical equations were used to estimate the values of these constants. These equations are 


$$
R_{C E}=1.58 \times 10^{-5} \frac{f_{i j}<\bar{G}_{k l}>}{x T_{e}^{T / 2}} \exp \left(-\frac{x}{T_{e}}\right) n_{e}
$$

where $R_{C E}$ is the collisional excitation rate constant, $f_{i j}$ is the oscillator strength for absorption, a unitless term, $\left\langle G_{k l}\right\rangle$ is the thermally averaged Gaunt factor, a unitless term $x$ is the transition energy in electronvolts, $T_{e}$ is the electron temperature, also in electronvolts and $n_{e}$ is the electron density, in electrons $/ \mathrm{cm}^{3}$ (ref. 15).

(2) collisional decay

$$
R_{C D}=1.58 \times 10^{-5}\left(\frac{g_{i}}{g_{j}}\right) \frac{f_{1 j}\left\langle\bar{G}_{k l}>\right.}{x T_{e}^{1 / 2}} n_{e}
$$

where $R_{C D}$ is the rate constant for collisional decay, $g_{i}$ is the statistical weight of the lower electronic state and $g_{j}$ is the statistical weight of the upper electronic state (ref. 15).

(3) radiative decay

$$
R_{R D}=A_{j 1}
$$

where $R_{R D}$ is the rate constant for radiative decay and $A_{j 1}$ is the Einstein transition probability (ref. 15).

These rate constants permit a steady-state model to be formulated, allowing an estimate of the populations of the eleven states included in this model.

\section{The Kinetic Steady-State (KSS) Model}

Although eleven states of the molybdenum atom are used in estimating the molybdenum atom population in the plasma, a four level, atomic system will be used to simplify the presentation of equations in this section. Figure 1 shows this arbitrary system, composed of a ground state and three low-lying excited states. The states have been numbered so that state 1 corresponds to the ground state and state 4 corresponds to the highest excited state considered. All of the following equations can be easily extended to eleven or more levels.

The steady-state assumption requires that after a sufficient time, the rates of change of the populations of all levels of a system will balance, so that no net changes will occur, in the absence of a perturbation which affects the rate of one of the important processes. This can be stated mathematically for the simplified system as 


$$
\begin{array}{r}
-R_{11} n_{1}+R_{12} n_{2}+R_{13} n_{3}+R_{14} n_{4}=0 \\
R_{21} n_{1}-R_{22} n_{2}+R_{23^{n_{3}}}+R_{24} n_{4}=0 \\
R_{31} n_{1}+R_{32^{n_{2}}}-R_{33^{n_{3}}}+R_{34} n_{4}=0 \\
R_{41^{n_{1}}}+R_{42^{n_{2}}}+R_{43^{n_{3}}}-R_{44^{n_{4}}}=0
\end{array}
$$

Where $R_{i j}$ is the overall rate constant for populating state $i$ from state $j$. When $i$ equals $j$, the rate constant is a depopulation rate constant; when $i$ is not equal to $j$, the rate constant is a population rate constant. Note that the subscript order convention for the rate constants and rates is the opposite of the convention used for spectroscopic terms, such as $f_{1 j}$ and $A_{j i}$. This allows the standard mathematical convention of row, column subscripts for matrices to be preserved. Only the rates and rate constants share this convention. The $n_{j}$ in this equation is the population number density for state. $j$. These are the quantities to be solved for by this model. Each equation balances the rate of population of a level $i\left(\Sigma R_{i j} n_{j}\right)$ with the rate of depopulation of that level $\left(-R_{j} \eta_{j}\right)$; the sum of these two terms must, under steady-state conditions, equal zero (ref. 15).

A specific example of the calculation of the overall rate constants for both population and depopulation can be instructive. The subscripts used for the partial rate constants are in the form "process, transition". As an example, $R_{C E, 21}$ is the partial rate constant for the process for collisional excitation for the transition which populates level 2 from level 1 . Here are three examples of the calculations of population/depopulation rate constants.

(a) $R_{21}=R_{C E, 21}$ (upward transition, population of level 2 from level 1)

(b) $R_{12}=R_{C D, 12}+R_{R D, 12}$ (downward transition, population of leve1 1 from

(c) $R_{22}=R_{12}+R_{32}+R_{42}$ (overall depopulation rate constant)

$$
=\left(R_{C D, 12}+R_{R D, 12}\right)+R_{C E, 32}+R_{C E, 42}
$$

The overall depopulation rate constant for level 2 (eq. (10c)) warrants an explanation. The depopulation rate constant for leve 12 is equal to the sum of all the overall rate constants, by which level 2 populates all other levels; the first equation represents this equality. The second equation expresses the overall depopulation rate constant in terms of partial rate constants. Since $R_{12}$ is a downward transition; the first two partial rate constants express the effects of both collisional and radiative decay on that transition. $R_{32}$ and $R_{42}$ are upward transitions, the overall rate constant for each of these transitions is equal to the partial rate constant for collisional excitation for that process. Each overall rate constant is created in this way to form the rate constants in equation set (9). 
Equation set (9) can be rewritten in matrix form.

$$
\left(\begin{array}{cccc}
-R_{11} & R_{12} & R_{13} & R_{14} \\
R_{21} & -R_{22} & R_{23} & R_{24} \\
R_{31} & R_{32} & -R_{33} & R_{34} \\
R_{41} & R_{42} & R_{43} & -R_{44}
\end{array}\right)\left(\begin{array}{l}
n_{1} \\
n_{2} \\
n_{3} \\
n_{4}
\end{array}\right)=\left(\begin{array}{l}
0 \\
0 \\
0 \\
0
\end{array}\right)
$$

This matrix equation is composed of a rate constant matrix, the population vector and a zero vector. The use of standard methods to solve this equation typically yields a result of zero for all the members of the population vector. This trivial solution occurs due to the zero vector. Perturbing one of the elements of the zero vector slightly yields nonzero results for the members of the population vector. Unfortunately, these values are dependent on the value used to perturb the zero vector. If the value used for the perturbation is small compared to the actual population/depopulation rates occurring in the plasma, the results obtained for the $n_{j}$ values will be correct in a relative sense. It is conventional to normalize these relative population values (the $n_{j}$ vector) so that they sum to one.

Atomic theory predicts that an absolute population density of an upper electronic level can be predicted using the absolute intensity of a transition involving that upper state

$$
n_{j}=\frac{4 \pi 10^{7} I_{j j}}{h_{0} \ell A_{j l}}
$$

where $n_{j}$ is the absolute population of the upper state $j$ in atom/ $\mathrm{cm}^{3}, I_{j i}$ is the absolute intensity for the transition $\mathrm{j} \rightarrow \mathrm{i}$ in $\mathrm{W} \mathrm{cm}^{-2}$ ster-1, $\mathrm{h}_{0}$ is the energy of the transition in ergs, $\ell$ is the path length over which emission occurs, in $\mathrm{cm}$, and $A_{f 1}$ is the Einstein transition probability in transition atom-1 $s^{-1}$ (ref. 39). A single transition between any two of the eleven states considered in this model allows the relative population values to be converted into absolute population values using equation (12). A $n_{j}$ value is generated for the observed transition $j \rightarrow i$. The ratio between an absolute population density, $n_{j}$, and a desired absolute population density, $n_{k}$, is equal to the corresponding ratio between their relative population densities,

$$
\frac{n_{1}}{n_{k}}=\frac{n_{1}}{n_{k}}
$$

therefore,

$$
n_{k}=\frac{n_{j}}{n_{j}} n_{k}
$$

If the desired $n_{k}$ value is the total molybdenum atom population density, $\mathrm{n}_{\mathrm{T}}$, equation (14) becomes 


$$
n_{T}=\frac{n_{j}}{n_{j}}
$$

since $n_{k}=n_{T}=1$, if the relative population densities have been normalized to one.

It would be advantageous to use several absolute intensity values, allowing several predictions of the conversion factor needed to change $n_{k}$ to $n_{k}$. General agreement of the resulting conversion factors indicates the model is correctly predicting the behavior of the physical system.

Tables II (a) to $(j)$ present the calculated $n_{j}$ values from program KSS. Each table contains the data for one value of electron temperature and several values of electron density. The data are presented in an exponential format for each of the terms, $7.15 \mathrm{e}-7$ stands for $7.15 \times 10^{-7}$. Since these are relative population values, they are dimensionless. As can be seen from these tables, the percentage of atoms in the ground state never falls below 99.8 percent for any combination of electron temperature and density; this value lies well above the 1 imit of 90 percent mentioned previously. The use of eleven levels should thus adequately model the spectral behavior of molybdenum in the ion thruster plasma.

For electron temperatures and densities which are within the bounds of these tables, but are not explicitly tabulated, linear interpolation can be used to find an approximate value for $n_{j}$.

\section{APPLICATION OF KSS MODEL TO EVALUATION OF SCREEN GRID LIFETIME}

As has been stated, the goal of this study is to find a method of correlating real-time spectroscopic data from ion thruster emission to the sputtering (1ifetime) of its screen grid. The formulated KSS model has provided a means of calculating $\eta_{j}$, the fraction of excited atoms of sputtered molybdenum as a function of electron temperature and density. In this section, $n j$ will be related to the sputtering rate of the target as a function of the ion thruster operating parameters. Before the theory can be compared to measured emission intensity data from an ion thruster, the sputtering rate of the screen grid has to be determined by calculated or measured sputtering yields as well as the plasma properties of the 8 - and $30-\mathrm{cm}$ thruster discharge chamber defined as a function of the thruster operating parameters. In addition, this discussion should also lead to a better understanding of the problems associated in evaluating thruster lifetime in general.

\section{Sputtering Rate Calculations}

The sputtering of the upstream side of the ion thruster has been deter mined to be one of the main life-limiting phenomena of ion thrusters (refs. 22 to 24). The sputtering rate of an ion thruster screen grid bombarded by ions can be calculated from equation (18) (refs. 24 and 25):

$$
R=\frac{J_{B}}{2 q n F \varphi_{S} A_{B}} \frac{\left[2 S_{+}(E)+\left(J^{++} / J^{+}\right) S_{++}(E)\right]}{\left(1+\left(J^{++} / J^{+}\right)\right)}
$$


where:

$\begin{array}{ll}J_{B} & \text { beam current } \\ q & \text { electronic charge } \\ n & \text { density of target material } \\ F & \text { beam flatness parameter } \\ \varphi_{S} & \text { screen grid effective transparency. } \\ A_{B} & \text { beam area } \\ S_{+}(E), S_{++}(E) & \text { sputter yields of singly and doubly charged ions } \\ J^{+}+/ J^{+} & \text {ratio of doubly to singly charged ion current density } \\ E & \text { ion energy }\end{array}$

Beatie (ref. 25) has derived the following empirical expressions for $E$ and $\varphi_{S}$ for a $30-\mathrm{cm}$ mercury ion thruster.

$$
\begin{gathered}
E=1.28 V_{D}-9.38 \text { (volts) } \\
\varphi_{S}=0.78+0.084 V_{T}-0.062 J_{B}
\end{gathered}
$$

where:

$V_{D}$ discharge voltage, $V$

$V_{T} \quad$ total accelerating voltage, $k V$

These expressions are not very sensitive to the operating parameters and, therefore, the assumptions will be made for the 8 -cm thruster that the ion energy is equal to the discharge voltage and the grid transparency is equal to the physical open area of the screen grid.

The sputtering rate $R$ can be also related to the sputtered atom total density, $n_{T}$, by:

where

$$
R=n_{T} V_{M o} \delta
$$

Vo average sputtered atom velocity

$\delta$ cross sectional area of the discharge

By combining equations (12), (15), and (23) the sputtering rate can be finally related to the emission intensity of a particular transition as:

$$
R=\frac{4 \pi \times 10^{7} I_{j j} V_{M_{0}} \delta}{n_{j} A_{j j} h_{0} l}
$$


The relative sputtering rates at two thruster operating points thus becomes:

$$
\frac{R_{1}}{R_{2}}=\frac{\left(I_{j j}\right)_{1}\left(n_{j}\right)_{2}}{\left(I_{j i}\right)_{2}\left(n_{j}\right)_{1}}
$$

$V_{\text {Mo }}$ in equation (21) represents the sputtered molybdenum atom velocity term. This term is expressed as an energy because that is a customary method of reporting this value in the literature. Finding suitable absolute values for this term is not a trivial matter. Various researchers (refs. 26 to 32) have determined that this parameter ranges from a few to several tens of electronvolts for most target-ion combinations at the relatively low impact energies characteristic of ion thrusters. A value for the most probable ejection energy of the sputtered target material can be derived from collision cascade theory (ref. 32). This value, independent of incident ion energy, is roughly one-half the surface binding energy of the target material (ref. 28). Since the surface binding energy of molybdenum is $6.82 \mathrm{eV}$ (ref. 33), the most probable energy for sputtered molybdenum atoms would be $3.4 \mathrm{ev}$. The energy distribution of sputtered metal atoms tends to obey the following relationship

$$
\rho(E)=\frac{E}{(E+U)^{3}}
$$

where $\rho(E)$ is the differential flux of sputtered particies with an energy of $E$, and $U$ is the surface binding energy of the metal, in consistent units of energy. This distribution has a pronounced high energy tail; the average energy of sputtered atoms should therefore, be signiffcantly higher than the most probable energy.

The sputtered atom velocity, $V_{M 0}$, has been assumed to be independent of incident ion energy. Should direct measurements of this parameter be reported in literature, they can be easily incorporated in the model.

To evaluate the spectroscopic model formulated in this study only relative sputtering rates are necessary. Therefore, for the same thruster configuration, using equation (18), the relative sputtering rates become:

$$
\frac{R_{1}}{R_{2}}=\frac{J_{B_{1}} \varphi_{S 2}(S(E))_{1}}{J_{B_{2}}^{\varphi}{ }_{S 1}(S(E))_{2}}
$$

where

$$
S(E)_{1}=\frac{\left[2 S_{+}(E)_{+}+\left(J^{++} / J_{+}\right)_{1} S_{++}(E)_{1}\right]}{\left(1+\left(J^{++} / J^{+}\right)_{1}\right)}
$$

Considerable amount of sputtering data has been accumulated over the years (refs. 34 and 35). However, reliable data, especially at ion energies near the sputtering threshold (region of operation of an ion thruster) is still rather scarce. Various models have been formulated for the sputter yields 
(ref. 36 to 39) but again, there is question as to their accuracy at very low ion energies (ref. 40). Bohdansky (ref. 39) has derived an expression for the sputtering yield for the threshold region as:

$$
S(E) \sim \propto S_{n}(E)\left[1-\left(\frac{E_{t h}}{E}\right)^{2 / 3}\right]\left[1-\left(\frac{E_{t h}}{E}\right)^{2}\right]
$$

where:

a energy independent function of the mass ratio between the target $\left(M_{2}\right)$ and ion projectile $\left(M_{1}\right)$

Eth sputtering threshold energy

$S_{n} \quad$ nuclear stopping cross section

Askerov and Sena have proposed an emperically formulated expression (ref. 41)

$$
S(E) \propto K\left(E-E_{t h}\right)^{3}
$$

Beatie has used an exponential function to approximate Askerov and Sena's data to calculate the lifetime of ion thrusters (ref. 25).

There is even considerate disagreement as to what the sputtering threshold energy should be. Experimental values for $\mathrm{Hg} \rightarrow$ Mo system (Mo screen grid and $\mathrm{Hg}$ propellant in an ion thruster) vary from 16 (ref. 41) to $32 \mathrm{~V}$ (ref. 42). A theoretical value as calculated by an expression formulated by Bohdansky is as high as $74 \mathrm{~V}$.

Figure 2 shows the comparison of normalized equations (26), (27), and the sputtering yield measurements of Askerov and Sena. For a best fit, a threshold value of $32 \mathrm{~V}$ was used with equation (26) and $16 \mathrm{~V}$ as measured by Askerov and Sena with equation (27). As suggested by Bohdansky, the $S_{n}(E)$ term was assumed to be energy independent in the ion energy range of interest. From figure 2, it is apparent that the best agreement with the measured data is obtained by equation (27) with $K=2.61 \times 10^{-8}$ and $E_{t h}=16.0 \mathrm{~V}$. This implies that Bohdansky's mode 1 and Askerov and Sena's data are not in complete agreement. Optical spectroscopy data from ion thrusters have indicated that sputtering threshold energies are considerably lower than the $32 \mathrm{~V}$ used in equation (26).

For these reasons, equation 27 represented the best available method for determining the sputtering yield in this study, even though theoretically it does not seem to have much justification. The sputter yield of double charged ions was assumed to be:

$$
S_{++}(E)=S_{+}(2 E) \text {. }
$$

The accuracy of equations (18) and (27) can be evaluated by comparing the calculated values with sputtering rate measurements of long term thruster life tests. Table III 1ists the life tests as summarized by Beatie (ref. 2). Comparison of sputtering rates in table III reveals very good agreement between ion thruster life-test results and the calculated rates using equation (18). 


\section{Ion Thruster Plasma Parameters}

The comparison of the spectroscopic model to measured intensity data requires the definition of the electron temperature and density as well as the doubly to singly charged ion current density ratio in calculating the sputtering rate as defined in the previous section. Analytical models have been developed to calculate these parameters (refs. 44 and 45), however, these calculations are rather complex. In this study, the plasma parameters were determined from either semiempirical equations or strictly empirical expressions obtained from a limited amount of probe data available in the 11terature. Data was characterized as either 8- (refs. 46 to 48) or $30-\mathrm{cm}$ (refs. 1 and 49 to 53) mercury ion thruster data. Possible differences between thrusters of the same size as grid and baffle configurations or other geometrical variations were ignored in applying the probe data in the literature to the study discussed herein.

Electron temperature and density. - It has been recognized that in an ion thruster more than one electron density distribution is possible. Electrons may exhibit what is referred to as primary electron distribution in which the electrons have energies that of the plasma potential or it is possible for the electrons to have undergone sufficient thermalization collisions resulting in a Maxwellian distribution. Most recent probe data (ref. 1) indicates that Maxwellian electron distributions dominate in both thruster sizes, therefore, only the Maxwellian electron distribution will be considered.

The Maxwellian temperature $T_{M}$ is related to the ionization rate factor $Q_{0}^{+}$defined as:

$$
Q_{0}^{+}=\frac{\sqrt{\frac{2 e}{m_{e}}} \int_{0}^{\infty} \sigma_{T}(E) E e^{-E / T_{M}} d E}{\int_{0}^{\infty} E^{1 / 2} e^{-E / T_{M}} d E}
$$

where $e$ is the electronic charge, $m_{e}$ is the electron mass, oT(E) is the ionization collision cross section and $E$ is the electron energy.

Instead of solving equation 28 , the following, much simpler equations, as obtained from avallable probe data, will be used for the respective thruster sizes:

$$
\begin{aligned}
& \left(T_{M}\right)_{8}=\frac{1}{6.0 \times 10^{-2}} \ln \left(\frac{V_{D}}{20.3}\right) \quad \mathrm{eV} \\
& \left(T_{M}\right)_{30}=\frac{1}{9.0 \times 10^{-2}} \ln \left(\frac{V_{0}}{20.0}\right) \quad \mathrm{eV}
\end{aligned}
$$

The Maxwellian electron number density can be derived for an fon thruster as:

$$
n_{M} \propto \frac{J_{B}}{v_{B} A_{g} \varphi_{S}}
$$


Where $J_{B}$ is the ion beam current, $V_{B}$ is the ion Boehm velocity, $A_{g}$ is the area of the grids and $\varphi_{S}$ is the transparency of the grids.

The following equations, of the form of equation 30 , were obtained for the Maxwellian electron number density from avallable data for the 8 - and $30-\mathrm{cm}$ ion thrusters:

$$
\begin{aligned}
& \left(n_{M}\right)_{8}=\frac{8.73 \times 10^{9}\left(J_{B}\right)_{8}}{\sqrt{T_{e}}}\left(\frac{n}{\mathrm{~cm}^{3}}\right) \\
& \left(n_{M}\right)_{30}=\frac{1.2 \times 10^{17}\left(J_{B}\right)_{30}}{\sqrt{T_{e}}}\left(\frac{n}{\mathrm{~cm}^{3}}\right)
\end{aligned}
$$

where $\left(J_{B}\right)_{8}$ and $\left(J_{B}\right)_{30}$ are measured in $\mathrm{mA}$, and amps respectively. It is noted that the ratio of the two electron number densities, as calculated by equations (31a) and (31b) for a given beam current is very close to the ratio of the two thruster sizes as predicted by equation 30 (assuming the same grid transparency). The $30-\mathrm{cm}$ thruster parameters as expressed by equations (29b) and (31b) were obtained from data over a narrow thruster operating range. The probe data for varying beam current ranged from 1.0 to $2.0 \mathrm{~A}$ at a discharge voltage of $32 \mathrm{~V}$. The discharge voltage was varied from 29 to $36 \mathrm{~V}$ at a beam current of $2.0 \mathrm{~A}$ (ref. 52).

It should also be noted that severe plasma instabilities were observed by reference 47 in measuring the probe data of the $8-\mathrm{cm}$ thruster between discharge voltages of 30 to $40 \mathrm{~V}$ at discharge currents of greater than $1.0 \mathrm{~A}$. The quoted expressions, therefore, for the electron temperature and density may not be that accurate over the whole operating range of the $8-\mathrm{cm}$ ion thruster.

Doubly to single charged ion current density ratio. - The doubly to singly charged ion current density ratfo, $\mathrm{J}^{++} / \mathrm{J}^{+}$, can be calculated from the ratio of the respective number densities:

$$
\frac{n^{++}}{n^{+}}=\frac{Q_{+}^{++}}{\frac{V_{W}^{+} A_{W}+V_{B}^{++} A_{b}}{F^{++} \Omega n_{e}}}
$$

where $Q_{++}^{+}$is the doubly charged ionization rate coefficient, $V_{W}^{++}$and $V_{B}^{++}$ are the reduced ion and Boehm velocity of doubly charged ions, $A W$ is the effective area for ion loss at the wall, $A_{b}$ is the beam area, $F^{++}$is the uniformity factor for the density gradient and $\Omega$ is the ion-production volume. 
Again, for simplicity, the ratio was obtained from available probe data in the literature:

$$
\begin{aligned}
& \left(\frac{I^{++}}{I^{+}}\right)_{8}=1.67\left(V_{D}-28.8\right) \\
& \left(\frac{I^{++}}{I^{+}}\right)_{30}=1.3 \times 10^{-2} e^{8.8 n_{U}}
\end{aligned}
$$

where $n_{u}$ is the propellant mass utilization in percent. It is noted that the ratio was found not to correlate with the same parameter in both thrusters.

Triply charged ions have been observed in 30-cm thruster above discharge voltages of $32.5 \mathrm{~V}$ (ref. 53). Centerline measurements indicated ratios of only about 10 percent at a discharge voltage of $50 \mathrm{~V}$. This effect, however, was neglected.

\section{EXPERIMENTAL APPARATUS}

Two conventional 8 - and $30-\mathrm{cm}$ thrusters were used for the optical spectrometer emission measurements. The $30-\mathrm{cm}$ thruster was equivalent to a "900" series EMT thruster described in reference 54 . The $8-\mathrm{cm}$ thruster was slightly modified from its baseline design to be able to operate at higher power levels. The description of this thruster in more detail is found in reference 55 . The $30-\mathrm{cm}$ thruster was operated in the 7.6-m diameter by $21.4-\mathrm{m}$ long vacuum faci1ity at NASA's Lewis Research Center. Its no load pressure was about $1.0 \times 10^{-7}$ torr. The $8-\mathrm{cm}$ thruster was operated in the 1.5 by $6.1 \mathrm{~m}$ vacuum tank, capable of about $5.0 \times 10^{-7}$ torr pressure at no load conditions.

A Jarre1-Ash, Mode $182-000$ series $0.5 \mathrm{~m}$ Ebert scanning emission spectrometer with an electric drive was used with a strip chart recorder to monitor the spectral line intensities emanating from the ion thruster. The spectrometer was located at the opposite end of the facllity in which the thruster was operated. The quartz window through which the spectrometer viewed the thruster was in a direct path of the beam current inside the facility. This configuration proved to be the most successful in ensuring that the quartz window remained clean from sputter deposition and facility oil residue. A slit on the spectrometer, usually set about 75 microns, viewed the entire diameter of the thruster (about 5 percent of the beam area). The results of measurements obtained with the $30-\mathrm{cm}$ thruster in studying the effect of background pressure on the sputtering rate of thruster components can be found in references 43 and 1 . Whereas, various lines of mercury and molybdenum were observed, only the MoI 3789 \& line intensities will be discussed herein. 


\section{RESULTS AND DISCUSSION}

\section{Comparison Between Model and Measured Intensity}

The relative intensity ratio at two thruster operating points from equation 25 becomes:

$$
\frac{I_{1}}{I_{2}}=\frac{\left[n_{j}\right] R_{2}}{\left[n_{j}\right]_{1} R_{2}}
$$

where $R$ can be thought of as the total number of sputtered atoms (assuming constant sputtered ion velocity) and $\eta_{j}$ as the fraction of excited sputtered atoms.

The simplest condition to evaluate in an operating thruster is when ion energy is varied without affecting the plasma parameters, namely changing $R$ without changing $n_{j}$. This condition approximates Wehner's experimental study of sputtering at low ion energies with an optical emission spectometer. In an ion thruster, this condition can only be achieved by electrically insulating the screen grid from the discharge chamber and then applying a negative bias to the screen grid with respect to the discharge chamber. The ion energy, in this case, was calculated by modifying equation (19) as:

$$
(E)_{30}=1.29\left(V_{D}\right)-9.38+V_{\text {bias }}
$$

The comparison of the measured relative intensity of the MoI 3798 \& line and the calculated sputtering rate ratio with an applied bias to the $30-\mathrm{cm}$ thruster screen grid is seen in figure 3. The direct sputtering rate measurements of Askerov and Sena and sputter yields as determined by equation (27) were used to calculate the two normalized intensities. It is apparent that excellent agreement is achieved with the absolute sputtering yields and satisfactory agreement is obtained with equation (27). The discrepancy may partly be due to an overestimation of the sputter yield by equation (27) at ion energies of greater than $80 \mathrm{~V}$ as seen in figure 2. The comparison, of course, is based on the assumption that changes in the measured intensity are the direct result of changes of the sputtering of the screen grid only. As later will be demonstrated, sputtered molybdenum intensity can change by other mechanisms. The relatively good agreement between the calculated and measured intensities validates the use of equation (27) for the sputter yield as well as justifying the assumption of constant sputtered ion velocity with ion energy discussed previously.

Once the discharge conditions are changed, the physical conditions inside the plasma are changed and the situation becomes much more complicated as compared to the simple case just discussed. The relative population levels of the excited sputtered atoms $n_{j}$ must be considered.

The analytical model formulated for $n_{j}$ appears in the first part of the paper and listed in table $I$. Values of $n j$ were obtained for the selected transition (in this case the MoI $3798 \AA 1$ ine) by the proper choice of electron temperature and density for a particular thruster operating point. The plasma parameters were determined by equations (29), (31), and (33) at the given thruster operating parameter. 
It should be pointed out that the plasma parameters from the thruster centerline were utilized, whereas, the spectrometer observed the entire diameter of the thruster. However, comparison of intensities measured at the center of the thruster with those measured across the entire diameter indicate that this discrepancy should not be of any significance (ref. 1).

Figure 4 shows the comparison of the measured and calculated relative intensity of the MoI 3798 A 1 ine as a function of discharge voltage of the $30 \mathrm{-cm}$ thruster. The increased intensity with discharge voltage is associated mainly with the increasing sputtering rate with ion energy. The fraction of excited sputtered atoms, $n_{j}$, remains relatively constant with discharge voltage. The agreement between the model and the measured intensities is good considering the many assumptions made in the model for calculating $\mathrm{nj}$, and the simplification and extrapolation of the plasma parameters by equations (29), (31), and (33). The lower than expected intensity measurements at the low ion energy range may be partly due to the attenuating effects on sputtering due to background gases of the vacuum facility.

Figure 5 shows the relative MoI intensity as a function of beam current. In this case, the increase in intensity with increasing beam current is associated with both increased sputtering rate (proportional to the beam current) and the increase in the fraction of excited spultered atoms, $n_{j}$. The increase in $\eta_{j}$ with increasing beam current is due to an almost linear increase of electron density with beam current. The electron temperature was assumed to be constant. Again, part of the discrepancy at the low beam current range may be due to the effects of background gases on the sputtering rate as mentiuned before. The assumption of constant electron temperature may also not be. strictly valid.

The baseline 8 -cm thruster has only one propellant inlet as compared lo two of the $30-\mathrm{cm}$ thruster. This restriction of the smalier thruster does not always allow independent thruster parameter variation as is posstble with the larger thruster. The beam current in the $8-\mathrm{cm}$ thruster is increased by increasing the propellant flow rate through the cathode allowing the discharge voltage to reach its desired value. Figure 6 shows the relative intensity of an $8-\mathrm{cm}$ thruster as a function of discharge voltage. The value of the beam current increased from $106.3 \mathrm{~mA}$ at at discharge voltage of $30 \mathrm{~V}$ to $211 \mathrm{~mA}$ at $25.4 \mathrm{~V}$ as indicated at each data point. The sputtered molybdenum intensity is expected to decrease with decreasing discharge voltage, but the decrease is moderated by increasing beam current and associated increase in $\eta_{j}$. As mentioned before, the probe data of the $8-\mathrm{cm}$ thruster between 30 and $40 \mathrm{~V}$ of discharge voltage was severely impacted by plasma instabilities, making an accurate determination of the plasma parameter difficult. The large discrepancy at the low discharge voltages was not, however, mainly due to the lack of accurate plasma parameters. It was surmised that the large increase of intensity at the low discharge voltage was mainly due to increased ion impingement on the accelerator grid. It was noted that as the beam current increased, accelerator impingement current significantly increased due to poor perveance or misalignment of the grids. The evidence leading to this conclusion is the increasing accelerator current to beam current ratio as the intensity is observed to increase. (MoI intensity has been observed to increase suddenly when ion beams have been intentionally defocused.)

Figure 7 shows the relative MoI intensity as a function of beam current with the discharge voltage constant (this is possible only at low discharge 
voltages for the 8-cm thruster). The agreement between theory and measured intensity appears to be very good in this case.

\section{Optical Spectroscopy as a Technique for Determining Thruster Lifetime}

It appears that the model developed to correlate spectroscopic emission intensity to the sputtering rate of a thruster component holds some promise as a technique for rapid determination of thruster lifetime. Satisfactory agreement was attained between measured emission intensity and calculated intensities of 8 - and $30-\mathrm{cm} \mathrm{Hg}$ ion thrusters, despite less than perfect definition of plasma parameters and sputtering yields at very low ion energies. For the $\mathrm{Hg} \rightarrow$ Mo system considered in this study, sputter yields have been measured with ion energies as low as $40 \mathrm{~V}$. For other propellant - target combinations, this is not the case. For example, $X e \rightarrow$ Mo sputtering yields are not avallable below $100 \mathrm{~V}$. It was concluded before that theoretical models developed for sputtering yields at low energies still appear to be inadequate. Thus it is for such propellant-target combinations that the optical spectroscopy technique may offer the most promising possibilities. The requirements for such an application are improved definition of plasma parameters as a function thruster operating parameters. The population levels of excited Mol, $n_{j}$, as a function of electron density and temperature, have been already determined in this study. The measurement of the excited MoI relative intensity, therefore, should result in an estimate of a xenon ion thruster lifetime by calculating the sputtering rate $R$ by equation (34). The relative intensity measurements taken below discharge voltages of $100 \mathrm{~V}$ can be converted to absolute sputtering rates by normalizing the measured intensity to the measured sputtering rates at $100 \mathrm{~V}$ and above.

\section{CONCLUSIONS}

An analytical model has been formulated to correlate the measured emission intensity of excited sputtered atoms in an ion thruster to the sputtering of thruster discharge components such as the screen grid. First, however, the thruster discharge plasma was characterized in regard to the classical spectroscopic parameters such as equilibrium conditions and optical depth of the plasma. It was established that the plasma is not in Local Thermal Equilibrium (LTE) and that the plasma is optically thin (no loss of radiation inside the plasma).

The model to calculate population densities of various transitions used a kinetic steady-state approach balancing the rates of population and depopulation of ten low-lying excited states of the sputtered MoI atom with those of the ground state. This was done to relate the spectral intensities of the various transitions of MoI to the population densities of the ten various states of the atom. Once this is done, the population density can be related to the sputtering rate of the target. Two modes of sputtered atom excitation and decay (radiative and collisional) were considered.

Since actual data has not been published of MoI excitation rate constants, semiempirical expressions were used. A computer was utilized to solve the 10 by 10 matrix of rate equations in obtaining the excited sputtered atom density as a function of electron temperature and density. 
The calculated relative intensity of MoI $3798 \AA$ was compared to measured relative emission intensities of the same transition from 8 - and $30-\mathrm{cm}$ mercury ion thrusters using semiempirical equations for the electron density, temperature and sputtering yields of a $\mathrm{Hg} \rightarrow$ Mo system. Excellent agreement between theory and data was found for the special situation in a thruster where the ion energy is varied without changing the plasma parameters. (This was accomplished by biasing the screen grid negatively with respect to the discharge chamber.)

Satisfactory agreement between calculated intensities and relative measured intensities was obtained when intensities were measured as a function of beam current (at constant discharge voltage) and as a function of discharge voltage (at constant beam current), for the $30-\mathrm{cm}$ thruster. Agreement between the theory and data was not, however, satisfactory for the intensity measure-ments of $8-\mathrm{cm}$ thruster as a function of discharge voltage (with varying beam current). However, most of this discrepancy can be related to the emission created by ion impingement on the accelerator grid due to poor perveance or grid misalignment. Part of the discrepancy may be also due to insufficiently accurate definition of electron density and temperature in the 8-cm thruster. This was a result of instabilities experienced during probe measurements over a wide range of thruster operating parameters.

The technique formulated, however, appears to hold promise for rapid evaluation of thruster lifetimes, especially in configurations where sputtering yields at low ion energies are not available in the literature (e.g., inert gas ion thruster systems). 
Much of the data required for the KSS model involves properties of the screen grid material, molybdenum. The spectroscopic system under consideration for molybdenum is shown in figure $A(1)$. Ten levels, representing lowlying excited states, are shown, along with the ground state of molybdenum. These levels form five sets of levels, the single ${ }^{7} \mathrm{~S}$ ground state leve1, a pair of $5 p$ levels, two sets of $7 p$ levels, each containing three levels and a pair of 7D levels. The two sets of 7p levels are prefixed with " $y$ " and " $z$ ", representing the lower and upper set of 7p states, respectively.

Table A-1 presents some important data for this system. The first column shows the term symbol for each of the eleven levels. The second column gives the wavelength for the resonance transition, the transition between this level and the ground state, in $A$. Column 3 presents the frequency of that trans 1 tion, in $s^{-1}$. In column 4 the statistical weight of the level is given; a dimensionless number.

Columns 5 and 6 of Table A-1 show the energy values for the 10 transitions comprising this system, in both eV and ergs. Both of these units are useful for certain calculations; both are derived from the wavelength data and are included here for ease of reference.

Equations (6) and (7) of this report require the absorption oscillator strength, $f_{i j}$, as part of their input data requirements, while equation (8) requires the related parameter, $A_{j j}$, the Einstein transition probability. Several sources tabulate oscillator strengths and transition probabilities (refs. 12, 43, 44,56, and 57), including one source which attempts to evaluate the quality of these values (ref. 12). Several works have recently been published on the lifetimes of various molybdenum atom states (refs. 58 and 59). If only resonance transitions are considered significant, the following equation converts lifetime to absorption oscillator strength

$$
f_{i j}=1.499 \times 10^{-7} \frac{g_{j}}{g_{i}} \frac{\lambda^{2}}{\tau}
$$

where $\tau$ is the lifetime of the state in $n s, \lambda$ is the wavelength in $A$, $g_{j}$ and $g_{i}$ are the dimensionless statistical weights of the upper and lower states, respectively and $f_{i j}$ is the absorption oscillator strength, which is also dimensionless (ref. 60). If the absorption oscillator strength is known, the Einstein transition probability can be easily found via

$$
A_{j i}=\frac{0.6670 \times 10^{-16}}{\lambda^{2}} \frac{g_{j}}{g_{j}} f_{1 j}
$$

where $\lambda$ is in $\AA$ and $A_{j j}$ is in $s^{-1}$ (ref. 60). Table A-2 presents the upper state lifetimes, the calculated absorption oscillator strengths and the Einstein transition probabilities. For resonance transitions, the Einstein transition probabilities are equivalent to the reciprocals of the lifetimes of the upper state; this serves as a check of the results of equations (AI) and $(A 2)$. 
TABLE A1. - MOLYBDENUM TERM SYMBOLS, WAVELENGTHS,

FREQUENCIES, AND STATISTICAL WEIGHTS FOR THE ELEVEN LEVEL SYSTEM ${ }^{\mathrm{a}}$

\begin{tabular}{|c|c|c|c|c|c|}
\hline $\begin{array}{l}\text { Term } \\
\text { symbol }\end{array}$ & $\lambda$, & $\begin{array}{l}v \\
H z\end{array}$ & g & $\begin{array}{l}E, \\
e V\end{array}$ & $\begin{array}{l}E, \\
\text { ergs }\end{array}$ \\
\hline & -.-.- & 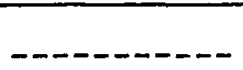 & 7 & $-\ldots--$ & ---1--n- \\
\hline$z^{7} P_{2}$ & 3903.0 & $7.6811 \times 10^{14}$ & 5 & 3.1769 & $5.0896 \times 10^{12}$ \\
\hline & 3864.1 & 7.7584 & 7 & 3.2089 & 5.1409 \\
\hline & 3798.3 & 7.8928 & 9 & 3.2645 & 5.2299 \\
\hline & 3466.8 & 8.6475 & 5 & 3.5767 & 5.7300 \\
\hline & 3456.4 & 8.6735 & 7 & 3.5874 & 5.7473 \\
\hline & 3208.8 & 9.3428 & 5 & 3.8642 & 6.1907 \\
\hline${ }^{y} P_{2}$ & 3194.0 & 9.3861 & 5 & 3.8821 & 6.2194 \\
\hline$y^{7} P_{3}$ & 3170.3 & 9.4563 & 7 & 3.9112 & 6.2659 \\
\hline & 3158.2 & 9.4925 & 7 & 3.9261 & 6.2899 \\
\hline$y^{7} P_{4}$ & 3132.6 & 9.5701 & 9 & 3.9582 & 6.3412 \\
\hline
\end{tabular}


TABLE A2. - MOLYBDENUM UPPER STATE LIFETIMES, ABSORPTION OSCILLATOR STRENGTHS, AND TRANSITION PROBABILITIES

\begin{tabular}{|c|c|c|c|c|c|c|c|c|}
\hline \multirow[t]{2}{*}{ Term } & \multicolumn{2}{|c|}{$\begin{array}{c}\text { Upper state } \\
\text { lifetime, } \\
\text { ns }\end{array}$} & \multicolumn{3}{|c|}{$\mathrm{AJj}_{\mathrm{Hz}} 10^{-7}$. } & \multicolumn{3}{|c|}{$f_{1 j}$} \\
\hline & (a) & (b) & (a) & (b) & $(c, d)$ & (a) & (b) & $(c, d)$ \\
\hline${ }^{5} P_{2}$ & 22.1 & --- & $d_{4.525}$ & ------ & ------- & $d_{0.05823}$ & ------ & ------- \\
\hline & 22.3 & $-\ldots$ & 4.484 & $\ldots$ & 0.2147 & 0.08031 & $-\cdots$ & 0.003845 \\
\hline$z^{7} P_{2}$ & 17.1 & 16.3 & 5.848 & 6.135 & 9.089 & 0.09536 & 0.1001 & .1483 \\
\hline$z^{7} P_{3}$ & 17.0 & 15.8 & 5.882 & 6.329 & 6.530 & . 1317 & 列. 1417 & .1462 \\
\hline$z^{7} P_{4}$ & 15.9 & 14.7 & 6.289 & 6.803 & 5.267 & 列. 1749 & 1891 & . 1465 \\
\hline$y^{7} P_{2}$ & --- & 6.6 & -..-. & 15.15 & 20.54 & $-\ldots-$ & .1655 & .2244 \\
\hline$y^{7} p_{3}$ & $-\ldots$ & 7.3 & --..-- & 13.70 & 12.21 & $\ldots$ & .2064 & .1840 \\
\hline$y^{7} p_{4}$ & ---- & 5.6 & --.--- & 17.86 & 12.86 & - & .3378 & .2431 \\
\hline${ }^{7} \mathrm{O}_{2}$ & -..- & 35.6 & $\ldots$ & 2.809 & 4.155 & - & .03097 & .04582 \\
\hline${ }^{7} D_{3}$ & --- & 21.2 & -.--- & 4.717 & 4.469 & & .07052 & .06682 \\
\hline
\end{tabular}

a Reference 58 .

bReference 59 .

CReference 61 .

dUsed for generating tabies II a to $j$. 


\section{REFERENCES}

1. Poeschel, R.L. and Beattie, J.R., "Primary Electric Propulsion Technology Study," NASA CR-159688, 1979.

2. Beattie, J.R., "Endurance Test of a 30-cm Diameter Engineering Model Ion Thruster - Investigation of Thin-Film Erosion Monitors for Ion Thrusters," NASA CR-168132, 1983.

3. Rock, B.A. and Parsons, M.L., "Rapid Evaluation of Ion Thruster Lifetime Using Optical Emission Spectroscopy," NASA CR-174741, 1984. (Not yet pub7ished.)

4. Wilson, R., "The Spectroscopy of Nonthermal Plasma," Journal of Quantitative Spectroscopy and Radiative Transfer, Vol. 2, 1962, pp. 477-490.

5. McWhirter, R.W.P., in Plasma Diagnostic Techniques, Academic Press, New York, 1965, pp. 201-264.

6. Griem, H.R., Plasma Spectroscopy, McGraw-Hill, New York, 1964, pp. 196-198.

7. Alkemade, C. Th. J., Hoolander, Tj., Snelleman, W., and Zeegers, P.J. Th., Metal Vapors in Flames, Pergamon Press, Oxford, 1982, pp. 125-129.

8. Alkemade, C. Th. J., Hoolander, Tj., Snelleman, W., and Zeegers, P.J. Th., Metal Vapors in Flames, Pergamon Press, 0xford, 1982, pp. 153.

9. Alkemade, C. Th. J., Hoolander, TJ., Snelleman, W. , and Zeegers, P.J. Th., Metal Vapors in Flames, Pergamon Press, Oxford, 1982, pp. 487.

10. Unpublished data, obtained from M. Mantenieks, NASA Lewis Research Center, Cleveland, $\mathrm{OH}, 44135$.

11. Mavrodineanu, R. and Boiteux, H., Flame Spectroscopy, Wiley, New York, 1965, p. 438.

12. Parsons, M.L., Smith, B.W., and Bently, G.E., Handbook of Flame Spectroscopy, Plenum Press, New York, 1975, pp. 295-334.

13. Lochte-Holtgreven, W., ed., Plasma Diagnostics, North Holland Publishing Co., Amsterdam, 1968, pp. 135-213.

14. Howatson, A.M., Introduction to Gas Discharges, 2nd ed., Pergamon Press, Oxford, 1976, pp. 134-135.

15. Lovett, R.J., "A rate model of inductively coupled argon plasma analyte spectra," Spectrochimica Acta, Vol. 37B (11), 1982, pp. 969-985.

16. Alkemade, C. Th. J., Hoolander, Tj., Snelleman, W., and Zeegers, P.J. Th., Metal Vapors in Flames, Pergamon Press, Oxford, 1982, pp. 107-109.

17. Wineforder, J.D., McGee, W.W., Mansfield, J.M., Parsons, M.L., and Zacha, K.E., "Intensity of Thermal Radiation of Metal Spectra in Flame Emission Spectrometry," Analytica Chimica Acta, Vol. 36, 1966, pp. 25-41. 
18. Peters, R.R., "Double Ion Production in Mercury Thrusters," NASA CR-135019, 1976.

19. M.L. Parsons, private communication.

20. Bauer, B. and Bartkey, C.D., "Calculation of Inelastic Electron-Molecule Collision Cross Sections by Classical Methods," Journal of Chemical Physics, Vo1. 42, July 1965, pp. 2466-2476.

21. Sears, F.W. and Zemansky, M.W., University Physics, 4th ed., Addison-Wesley Pub. Co., Reading, MA, 1970, pp. 118-120.

22. Collett, C.R., "Thruster Endurance Test," NASA CR-135011, 1976.

23. Collett, C.R. and Bechtel, R.T., "An Endurance Test of a 900 Series 30-cm Engineering Mode1 Ion Thruster," AIAA Paper 76-1020, November 1976.

24. Mantenieks, M.A. and Rawlin, V.K., "Sputtering Phenomena of Discharge Chamber Components in a 30-cm diameter Hg Ion Thruster," AIAA Paper 76-988 November 1976.

25. Beattie, J.R., "A Model for Predicting the Wearout Lifetime of the LeRC/Hughes 30-cm Mercury Ion Thruster," AIAA Paper 79-2079, October 1979.

26. Oechsner, H., "Sputtering. Review of Some Recent Experimental and Theoretical Aspects," Applied Physics, Vol. 8, March 1975, pp. 185-198.

27. Wehner, G.K. and Anderson, G.S., in Handbook of Thin Film Technology, McGraw-Hi11, New York, 1970, pp. 1-38.

28. Greene, J.E. and Barnett, S.A., "Ion-surface Interactions During Vapor Phase Crystal Growth by Sputtering, MBE, and Plasma-Enhanced CVD: Applications to Semiconductors," Journal of Vacuum Science Technology. Vo1. 21, no. 2, 1982, pp. 285-302.

29. Stuart, R.V., Wehner, G.K., and Anderson, G.S., "Energy Distribution of Atoms Sputtered from Polycrystalline Metals," Journal of Applied Physics, vol. 40 , no. 2 , 1969 , p. 803-812.

30. Wehner, G.K., "Forces on Ion-Bombardment Electrodes in a Low-Pressure Plasma," Journal of Applied Physics, Vol. 31, no. 8, 1960, pp. 1392-1397.

31. Harper, J.M.E., Cuomo, J.J., and Kaufman, F.R., "Technology and applications of Broad-beam Ion Sources in Sputtering -2. Applications," Journal of Vacuum Science Technology, Vo1. 21, no. 3, 1982, pp. 737-756.

32. Bernhardt, F., Oechsner, H., and Stumpe, E., "Energy Distributions of Neutral Atoms and Molecules Sputtered from Polycrystalline Silver," Nuclear Instruments and Methods, Vol. 132, 1976, p. 329-334.

33. Andersen, H.H. and Bay, H.L., "A Survey of Sputtering-Yield Data for Plasma-Wall Interaction Calculations," Journal of Nuclear Materials. Vol. 93-94 (B), 1980, pp. 625-633.

34. Behrish, R., ed., Sputtering by Particle Bombardment, (Topics in Applted Physics, Vo1. 47), Springer-Verlag, Berlin; New York, 1981. 
35. Roth, J., Bohdansky, J., and Ottenberger, "Data on Low Energy Light Ion Sputtering," IPP 9/26, Max-Planck-Institut Fur Plasmaphysic, 1979.

36. Harrison, Don E., Jr., "Sputtering Models - A Synoptic View," Radiation Effects, Vol. 70(1-4), 1983, pp. 1-64.

37. Yamamura, Y., Matsunami, N., and Itoh, N., "Theoretical Studies on an Empirical Formula for Sputtering Yield at Normal Incidence, Radiation Effects, Vo1. 71(1-2), 1983, pp. 68-86.

38. Strydom, H.J. and Gries, W.H., "A Comparison of Three Versions of Sigmund's Model of Sputtering Using Experimental Results," Radiation Effects Letters Section, Vol. 86(4), 1984, pp. 145-151.

39. Bohdansky, J., "A Universal Relation for the Sputtering Yield of Monatomic Solids at Normal Ion Incidence," Nuclear Instruments and Methods in Physics Research, Sect. B, Vol. 230(1), 1984, pp. 587-591.

40. Zalm, P.C., "A Critique of Semiempirical Formulas for the Sputtering Yield near Threshold Energy," Radiation Effects Letters Section, Vol. 86(1), 1983, pp. 29-34.

41. Askerov, Sh.G. and Sena, L.A., "Cathode Sputtering of Metals by Slow Mercury Ions," Soviet-Physics-Solid State, Vol. 11, no. 6, December 1969, pp. 1288-1293.

42. Stuart, R.V. and Wehner, G.K., "Sputtering Yields at Very Low Bombarding Ion Energies," Journal of Applied Physics, Vo1. 33, no. 7, 1962, pp. $2345-2352$.

43. Rawlin, V.K. and Mantenieks, M.A., "Effect of Facllity Background Gases on Internal Erosion of the 30-cm Hg Ion Thruster, "AIAA Paper 78-665, Apr 11 1978.

44. Longhurst, G., "Prediction of Plasma Properties in Mercury Ion Thrusters," NASA CR-159448, 1978.

45. Brophy, J.R., "Ion Thruster Performance Mode1," NASA CR-174810, 1984.

46. Wessel, F.J. and Williamson, W.S., "8-cm Ion Thruster Characterization," NASA CR-167887, 1983.

47. Wilber, P., "Advanced Space Propulsion Thruster Research," NASA CR-165584, 1981.

48. Hyman, J., Jr. and Williamson, W.S., "Ion Chamber Sputtering Investigation," Hughes Research Laboratory, Malibu, CA, Contract IS.-679, January 1977.

49. Poeschel, R.L., "2.5 kW Advanced Technology Ion Thrusters," NASA CR-135076, 1976.

50. Poesche1, R.L., "High-power and $2.5 \mathrm{~kW}$ Advanced Technology Ion Thruster," NASA CR-135163, 1977. 
51. Poesche1, R.L., "Extended Performance Solar Electric Propulsion Thrust System Study," NASA CR-135281, 1977.

52. Beattie, J.R., private communication.

53. Vahrenkamp, R.P., "Measurement of Double Charged Ions in the Beam of a 30-cm Mercury Bombardment Thruster," AIAA Paper 73-1057, November 1973.

54. Bechtel, T.R. and Raw1in, V.K., "Performance Documentation of the Engineering Mode1 30-cm Diameter Thruster," AIAA Paper 76-1033, November 1976.

55. Mantenieks, M.A., "Extended Performance 8-cm Mercury Ion Thruster," AIAA Paper 82-1913, November 1982.

56. Moore, C.E., Atomic Energy Leve1s, 1st ed., National Bureau of Standards, Washington, DC, 1958, Vol. III, pp. 1-6.

57. Corliss, C.H. and Bozman, W.R., Experimental Transition Probabilities for Spectral Lines of Seventy Elements, $1 \mathrm{~s}$ ed., National Bureau of Standards, Washington, OC, 1962, pp. 204-219.

58. Duquette, D.W., Salih, S., and Lawler, J.E., "Radiative lifetimes in Mol Using a Novel Atomic Beam Source," Physics Letters, Vo1. 83A, no. 5, 1981 , pp. 214-216.

59. Kwiatkowski, M., Micali, G., Werner, K., and Zimmerman, P., "Radiative Lifetimes and Oscillation Strengths in Mol," Physics Letters, Vol. 85A, no. 5, 1981, pp. 273-274.

60. Mavrodineanu, R. and Boiteux, H., Flame Spectroscopy, Wiley, New York, 1965, pp. 514-516.

61. Schnehage, S.E., Danzmann, K., Kuennemeyer, R., and Kock, M., "Oscillator Strengths of Neutral and Singly Ionized Molybdenum, " Journal of

Quantitative Spectroscopy and Radiative Transfer, Vo1. 29, no. 6, 1983, pp. 507-516.

62. Dulgeroff, C.R., Beattie, J.R., Poeschel, R.L., and Hyman, J., Jr., "Ion Thruster System (8-cm) Cyclic Endurance Test," NASA CR-174745, 1984. 
TABLE I. - ABSORPTIVITIES ( $k_{\text {max }}$ VALUES)

$\left[\left(n_{j}\right)_{M_{0}}=2.0 \times 10^{5}\right.$ atoms $\left./ \mathrm{cm}^{3}.\right]$

\begin{tabular}{|c|c|c|c|}
\hline Upper state & $\begin{array}{l}\mathrm{K}_{\max } \text { at } 500 \mathrm{~K}, \\
0.0431 \mathrm{eV}\end{array}$ & $\begin{array}{l}\mathrm{K}_{\max } \text { at } 11600 \mathrm{~K}, \\
1.0 \mathrm{eV}\end{array}$ & $\begin{array}{l}k_{\max } \text { at } 139200 \mathrm{~K} \text {, } \\
12.0 \mathrm{eV}\end{array}$ \\
\hline$z^{7} P_{2}$ & $1.2 \times 10^{-2} \mathrm{~cm}-1$ & $2.4 \times 10^{-3} \mathrm{~cm}-1$ & $7.0 \times 10-4 \mathrm{~cm}-1$ \\
\hline$z^{7} P_{3}$ & $1.2 \times 10^{-2}$ & $2.4 \times 10^{-3}$ & $7.0 \times 10^{-4}$ \\
\hline$z^{7} P_{4}$ & $1.2 \times 10^{-2}$ & $2.5 \times 10^{-3}$ & $7.1 \times 10^{-4}$ \\
\hline & $5.7 \times 10^{-3}$ & $1.1 \times 10^{-3}$ & $3.1 \times 10^{-4}$ \\
\hline & $3.4 \times 10^{-4}$ & $7.1 \times 10^{-5}$ & $2.0 \times 10^{-5}$ \\
\hline${ }^{7} \mathrm{D}_{2}$ & $4.4 \times 10^{-3}$ & $9.1 \times 10^{-4}$ & $2.6 \times 10^{-4}$ \\
\hline$y^{7} p_{2}$ & $2.1 \times 10^{-2}$ & $4.5 \times 10^{-3}$ & $1.3 \times 10^{-3}$ \\
\hline$y^{7} P_{3}$ & $1.8 \times 10^{-2}$ & $3.7 \times 10^{-3}$ & $1.1 \times 10^{-3}$ \\
\hline${ }^{7} \mathrm{D}_{3}$ & $6.5 \times 10^{-3}$ & $1.3 \times 10^{-3}$ & $3.9 \times 10^{-4}$ \\
\hline$y^{7} p_{4}$ & $2.4 \times 10^{-2}$ & $4.9 \times 10^{-3}$ & $1.4 \times 10^{-3}$ \\
\hline${ }^{3} \mathrm{P}_{1}$ & $4.1 \times 10^{+2}$ & $8.5 \times 10^{+1}$ & $2.5 \times 10^{1}$ \\
\hline
\end{tabular}


TABLE II. - RELATIVE POPULATION VALUES, $n_{j}$

(a) Electron temperature $=2.0 \mathrm{eV}$

\begin{tabular}{|c|c|c|c|c|c|c|c|}
\hline Term & $\begin{array}{l}\log _{10.50} n_{e} \\
10.5\end{array}$ & $\begin{array}{l}\log _{10.75} n_{e} \\
10.0\end{array}$ & $\begin{array}{l}\log _{11.00} n_{e} \\
11.00\end{array}$ & $\log _{11.25} n_{e}$ & $\begin{array}{l}\log _{11.50} \mathrm{n}_{\mathrm{e}} \\
11.5\end{array}$ & $\begin{array}{l}\log _{11} \mathrm{n}_{\mathrm{e}} \\
11.75\end{array}$ & $\begin{array}{l}\log \mathrm{n}_{\mathrm{e}} \\
12.00\end{array}$ \\
\hline & $1.00 \mathrm{e}-0$ & $1.00 \mathrm{e}-0$ & $1.00 \mathrm{e}-0$ & $1.00 \mathrm{e}-0$ & $1.00 \mathrm{e}-0$ & $1.00 e-0$ & $9.99 e-1$ \\
\hline & $1.45 e-6$ & $2.58 \mathrm{e}-6$ & $4.59 e-6$ & $8.16 e-6$ & $1.45 e-5$ & $2.58 e-5$ & $4.58 e-5$ \\
\hline & $2.00 e-6$ & 3.55 & $6.32 e-6$ & $1.12 e-5$ & $2.00 e-5$ & 3.55 & $6.37 e-5$ \\
\hline & $2.74 e-6$ & 4.86 & $8.65 e-6$ & $1.54 e-5$ & $2.73 e-5$ & 4.86 & $8.64 e-5$ \\
\hline & $3.63 e-6$ & 6.46 & $1.15 e-5$ & $2.04 e-5$ & $3.63 e-5$ & 6.45 & $1.15 \mathrm{e}-4$ \\
\hline & $4.26 e-6$ & 7.58 & $1.35 e-5$ & $2.40 e-5$ & $4.26 e-5$ & 7.58 & $1.35 e-4$ \\
\hline & $9.23 e-7$ & 1.64 & $2.92 e-6$ & $5.19 e-6$ & $9.22 e-6$ & 1.64 & $2.92 e \cdot 5$ \\
\hline & $7.23 e-6$ & 2.20 & $3.92 e-6$ & $6.97 e-6$ & $1.24 e-5$ & 2.20 & $3.92 e-5$ \\
\hline$y^{7} P_{4}$ & $1.49 e-6$ & 2.65 & $4.71 \mathrm{e}-6$ & $8.37 e-6$ & $1.49 e-5$ & 2.65 & $4.70 e-5$ \\
\hline & $9.47 e-7$ & 1.68 & $3.00 e-6$ & $5.32 e-6$ & $9.47 e-6$ & 1.68 & $2.99 e-5$ \\
\hline${ }^{7} \mathrm{D}_{3}$ & $1.21 e-6$ & $2.16 \downarrow$ & $3.83 e-6$ & $6.82 e-6$ & $1.21 e-5$ & 2.16 & $3.83 e-5$ \\
\hline
\end{tabular}

(b) Electron temperature $=3.0 \mathrm{eV}$

\begin{tabular}{|c|c|c|c|c|c|c|c|}
\hline 7 & $1.00 \mathrm{e}-0$ & $1.00 \mathrm{e}-0$ & $1.00 \mathrm{e}-0$ & $1.00 \mathrm{e}-0$ & $1.00 \mathrm{e}-0$ & $9.99 e-1$ & $9.99 e-1$ \\
\hline & $2.81 e-6$ & $5.00 e-6$ & $8.89 e-6$ & $1.58 \mathrm{e}-5$ & $2.81 e-5$ & $4.99 e-5$ & $8.88 e-5$ \\
\hline & 3.88 & $6.90 \mathrm{e}-6$ & $1.23 e-5$ & 2.18 & 3.88 & $6.89 e-5$ & 1. $.22 \mathrm{e}-4$ \\
\hline & 4.96 & $8.82 e-6$ & $1.57 e-5$ & 2.79 & 4.96 & $8.81 e-5$ & $1.56 \mathrm{e}-4$ \\
\hline & 6.62 & $1.18 \mathrm{e}-5$ & $2.09 e-5$ & 3.72 & 6.62 & $1.18 \mathrm{e}-4$ & $2.09 e-4$ \\
\hline & 7.85 & $1.40 \mathrm{e}-5$ & $2.48 e-5$ & 4.41 & 7.84 & $1.39 e-4$ & $2.48 e-4$ \\
\hline & 1.88 & $3.34 e-6$ & $5.95 e-6$ & 1.06 & 1.88 & $3.34 e-5$ & $5.94 e-5$ \\
\hline$y^{7}$ & 2.54 & $4.51 \mathrm{e}-6$ & $8.02 e-6$ & 1.43 & 2.54 & $4.51 e-5$ & $8.01 e-5$ \\
\hline$y^{7} p_{4}$ & 3.07 & $5.46 e-6$ & $9.71 e-6$ & 1.73 & 3.07 & $5.46 e-5$ & $9.70 e-5$ \\
\hline & 1.92 & $3.42 \mathrm{e}-6$ & $6.08 e-6$ & 1.08 & 1.92 & $3.42 e-5$ & $6.08 e-5$ \\
\hline${ }^{7} \mathrm{D}_{3}$ & 2.49 & $4.43 e-6$ & $7.87 e-6$ & 1.40 & $2.49 \downarrow$ & $4.42 e-5$ & $7.86 e-5$ \\
\hline
\end{tabular}


TABLE II. - Continued.

(c) Electron temperature $=4.0 \mathrm{eV}$

\begin{tabular}{|c|c|c|c|c|c|c|c|}
\hline Term & $\begin{array}{l}\log n_{e} \\
10.50 \\
\end{array}$ & $\begin{array}{l}9 \mathrm{n}_{\mathrm{e}} \\
0.75 \\
\end{array}$ & $\begin{array}{l}\log n_{e} \\
11.00\end{array}$ & $\begin{array}{l}\log \mathrm{ne}_{\mathrm{e}} \\
11.25\end{array}$ & $\begin{array}{l}\log \mathrm{ne}_{\mathrm{e}} \\
11.50\end{array}$ & $\begin{array}{l}\log n_{e} \\
11.75\end{array}$ & $\begin{array}{l}\log n_{e} \\
12.00\end{array}$ \\
\hline & $1.00 \mathrm{e}-0$ & $1.00 \mathrm{e}-0$ & $1.00 \mathrm{e}-0$ & $1.00 \mathrm{e}-0$ & $1.00 \mathrm{e}-0$ & $9.99 \mathrm{e}-1$ & $9.98 \mathrm{e}-1$ \\
\hline & $3.97 \mathrm{e}-6$ & $7.06 e-6$ & $1.26 \mathrm{e}-5$ & $2.23 e-5$ & $3.97 e-5$ & $7.05 e-5$ & $1.25 \mathrm{e}-4$ \\
\hline & $5.48 \mathrm{e}-6$ & $9.75 e-6$ & $1.73 e-6$ & 3.08 & $5.48 e-5$ & $9.74 e-5$ & $1.73 e-4$ \\
\hline & $6.77 e-6$ & $1.20 \mathrm{e}-5$ & $2.14 e-5$ & 3.81 & $6.77 e-5$ & $1.20 \mathrm{e}-4$ & $2.74 \mathrm{e}-4$ \\
\hline & $9.07 e-6$ & $1.67 \mathrm{e}-5$ & $2.87 e-5$ & 5.10 & $9.06 e-5$ & $1.67 \mathrm{e}-4$ & $2.86 e-4$ \\
\hline & $1.08 \mathrm{e}-5$ & $1.92 \mathrm{e}-5$ & $3.47 \mathrm{e}-5$ & 6.07 & $1.08 \mathrm{e}-4$ & $1.92 \mathrm{e}-4$ & $3.41 \mathrm{e}-4$ \\
\hline & $2.72 \mathrm{e}-6$ & $4.84 \mathrm{e}-6$ & $8.61 \mathrm{e}-6$ & 1.53 & $2.72 e-5$ & $4.84 e-5$ & $8.60 e-5$ \\
\hline$y^{7} P_{3}$ & $3.68 \mathrm{e}-6$ & $6.55 \mathrm{e}-6$ & $1.16 \mathrm{e}-5$ & 2.07 & $3.68 \mathrm{e}-5$ & $6.54 e-5$ & $1.16 e-4$ \\
\hline$y^{7} P_{4}$ & $4.48 \mathrm{e}-6$ & $7.96 e-6$ & $1.42 e-5$ & 2.52 & $4.48 \mathrm{e}-5$ & $7.95 e-5$ & $1.41 \mathrm{e}-4$ \\
\hline & $2.78 e-6$ & $4.95 \mathrm{e}-6$ & $8.80 e-6$ & 1.56 & $2.78 e-5$ & $4.94 \mathrm{e}-5$ & $8.78 e-5$ \\
\hline${ }^{7} D_{3}$ & $3.62 e-6$ & $6.44 e-6$ & $1.14 \mathrm{e}-5$ & $2.03 \downarrow$ & $3.62 e-5$ & $6.43 e-5$ & $1.14 \mathrm{e}-4$ \\
\hline
\end{tabular}

(d) Electron temperature $=5.0 \mathrm{eV}$

\begin{tabular}{|c|c|c|c|c|c|c|c|}
\hline${ }^{7} \mathrm{~S}_{3}$ & $1.00 \mathrm{e}-0$ & $1.00 \mathrm{e}-0$ & $1.00 \mathrm{e}-0$ & $1.00 \mathrm{e}-0$ & $9.99 \mathrm{e}-1$ & $9.99 \mathrm{e}-1$ & $9.98 \mathrm{e}-1$ \\
${ }^{5} \mathrm{P}_{2}$ & $4.92 \mathrm{e}-6$ & $8.76 \mathrm{e}-6$ & $1.56 \mathrm{e}-5$ & $2.77 \mathrm{e}-5$ & $4.92 \mathrm{e}-5$ & $8.74 \mathrm{e}-5$ & $1.55 \mathrm{e}-4$ \\
${ }^{5} \mathrm{P}_{3}$ & $6.80 \mathrm{e}-6$ & $1.21 \mathrm{e}-5$ & 2.15 & 3.82 & $6.80 \mathrm{e}-5$ & $1.21 \mathrm{e}-4$ & 2.15 \\
$\mathrm{z}^{7} \mathrm{P}_{2}$ & $8.24 \mathrm{e}-6$ & $1.46 \mathrm{e}-5$ & 2.60 & 4.63 & $8.23 \mathrm{e}-5$ & $1.46 \mathrm{e}-4$ & 2.60 \\
$\mathrm{z}^{7} \mathrm{P}_{3}$ & $1.10 \mathrm{e}-5$ & $1.96 \mathrm{e}-5$ & 3.49 & 6.21 & $1.10 \mathrm{e}-4$ & $1.96 \mathrm{e}-4$ & 3.48 \\
$\mathrm{z}^{7} \mathrm{P}_{4}$ & $1.32 \mathrm{e}-5$ & $2.34 \mathrm{e}-5$ & 4.17 & 7.41 & $1.32 \mathrm{e}-4$ & $2.34 \mathrm{e}-4$ & 4.16 \\
$\mathrm{y}^{7} \mathrm{P}_{2}$ & $3.43 \mathrm{e}-6$ & $6.10 \mathrm{e}-6$ & 1.08 & 1.93 & $3.43 \mathrm{e}-5$ & $6.09 \mathrm{e}-5$ & 1.08 \\
$\mathrm{y}^{7} \mathrm{P}_{3}$ & $4.65 \mathrm{e}-6$ & $8.26 \mathrm{e}-6$ & 1.47 & 2.61 & $4.64 \mathrm{e}-5$ & $8.25 \mathrm{e}-5$ & 1.47 \\
$\mathrm{y}^{7} \mathrm{P}_{4}$ & $5.66 \mathrm{e}-6$ & $1.01 \mathrm{e}-5$ & 1.79 & 3.18 & $5.66 \mathrm{e}-5$ & $1.00 \mathrm{e}-4$ & 1.79 \\
${ }^{7} \mathrm{D}_{2}$ & $3.50 \mathrm{e}-6$ & $6.23 \mathrm{e}-6$ & 1.11 & 1.97 & $3.50 \mathrm{e}-5$ & $6.22 \mathrm{e}-5$ & 1.10 \\
${ }^{7} \mathrm{D}_{3}$ & $4.57 \mathrm{e}-6$ & $8.12 \mathrm{e}-6$ & 1.44 & 2.57 & $4.56 \mathrm{e}-5$ & $8.11 \mathrm{e}-5$ & 1.44 \\
\hline
\end{tabular}


TABLE II. - Continued.

(e) Electron temperature $=6.0$

\begin{tabular}{|c|l|l|l|l|l|l|l|}
\hline Term & $\begin{array}{l}\text { log } n_{e} \\
10.50\end{array}$ & $\begin{array}{l}\log n_{e} \\
10.75\end{array}$ & $\begin{array}{l}\log n_{e} \\
11.00\end{array}$ & $\begin{array}{l}\log n_{e} \\
11.25\end{array}$ & $\begin{array}{l}\log n_{e} \\
11.50\end{array}$ & $\begin{array}{l}\log n_{e} \\
11.75\end{array}$ & $\begin{array}{l}\log n_{e} \\
12.00\end{array}$ \\
\hline${ }^{7} S_{3}$ & $1.00 e-0$ & $1.00 e-0$ & $1.00 e-0$ & $1.00 e-0$ & $9.99 e-1$ & $9.99 e-1$ & $9.98 e-1$ \\
${ }^{5} P_{2}$ & $5.72 e-6$ & $1.02 e-5$ & $1.81 e-5$ & $3.21 e-5$ & $5.71 e-5$ & $1.02 e-4$ & $1.80 e-4$ \\
${ }^{5} P_{3}$ & $7.90 e-6$ & $1.40 e-5$ & 2.50 & 4.44 & $7.90 e-5$ & $1.40 e-4$ & 2.49 \\
$z_{3}^{7} P_{2}$ & $9.44 e-6$ & $1.68 e-5$ & 2.98 & 5.30 & $9.43 e-5$ & $1.68 e-4$ & 2.98 \\
$z^{7} P_{3}$ & $1.27 e-5$ & $2.25 e-5$ & 4.01 & 7.12 & $1.27 e-4$ & $2.25 e-4$ & 3.99 \\
$z^{7} P_{4}$ & $1.52 e-5$ & $2.70 e-5$ & 4.79 & 8.52 & $1.51 e-4$ & $2.69 e-4$ & 4.78 \\
$y^{7} P_{2}$ & $4.02 e-6$ & $7.16 e-6$ & 1.27 & 2.26 & $4.02 e-5$ & $7.15 e-5$ & 1.27 \\
$y^{7} P_{3}$ & $5.46 e-6$ & $9.70 e-6$ & 1.72 & 3.07 & $5.45 e-5$ & $9.69 e-5$ & 1.72 \\
$y^{7} P_{4}$ & $6.66 e-6$ & $1.18 e-5$ & 2.10 & 3.74 & $6.65 e-5$ & $1.18 e-4$ & 2.10 \\
${ }^{7}{ }_{D_{2}}$ & $4.11 e-6$ & $7.30 e-6$ & 1.30 \\
${ }^{7}{ }_{D_{3}}$ & $5.37 e-6$ & $9.54 e-6$ & 1.70 & 2.31 & $4.10 e-5$ & $7.29 e-5$ & 1.30 \\
\hline
\end{tabular}

(f) Electron temperature $=7.0$

\begin{tabular}{|c|c|c|c|c|c|c|c|}
\hline$s_{3}$ & $1.00 \mathrm{e}-0$ & $1.00 \mathrm{e}-0$ & $1.00 \mathrm{e}-0$ & $1.00 \mathrm{e}-0$ & $9.99 \mathrm{e}-1$ & $9.98 \mathrm{e}-1$ & $9.97 \times 10-1$ \\
\hline & $6.39 e-6$ & $1.14 e-5$ & $2.02 e-5$ & $3.59 \mathrm{e}-5$ & $6.38 \mathrm{e}-5$ & $1.13 e-4$ & $2.01 \times 10-4$ \\
\hline & $8.83 e-6$ & $1.57 e-5$ & 2.79 & 4.96 & $8.82 e-5$ & $1.57 e-4$ & $2.78 e-4$ \\
\hline$z^{7} P_{2}$ & $1.04 \mathrm{e}-5$ & $1.86 e-5$ & 3.30 & 5.87 & $1.04 e-4$ & $1.85 e-4$ & 3.29 \\
\hline$z^{7} P_{3}$ & $1.40 \mathrm{e}-5$ & $2.50 e-5$ & 4.44 & 7.88 & $1.40 e-4$ & $2.49 e-4$ & 4.42 \\
\hline & $1.68 \mathrm{e}-5$ & $2.99 \mathrm{e}-5$ & 5.31 & 9.44 & $1.68 \mathrm{e}-4$ & $2.98 e-4$ & 5.30 \\
\hline$y^{7} P_{2}$ & $4.53 e-6$ & $8.05 e-6$ & 1.43 & 2.54 & $4.52 e-5$ & $8.04 e-5$ & 1.43 \\
\hline$y^{7} P_{3}$ & $6.14 e-6$ & $1.09 \mathrm{e}-5$ & 1.94 & 3.45 & $6.14 e-5$ & $1.09 e-4$ & 1.94 \\
\hline$y^{7} P_{4}$ & $7.50 e-6$ & $1.33 \mathrm{e}-5$ & 2.37 & 4.22 & $7.50 e-5$ & $1.33 e-4$ & 2.37 \\
\hline${ }^{7} \mathrm{D}_{2}$ & $4.62 e-6$ & $8.21 e-6$ & 1.46 & 2.60 & $4.67 e-5$ & $8.20 e-5$ & 1.46 \\
\hline${ }^{7} \mathrm{D}_{3}$ & $6.04 e-6$ & $1.08 e-5$ & $1.91 \downarrow$ & $3.40 \downarrow$ & $6.04 e-5$ & $1.07 e-4$ & $1.91 \downarrow$ \\
\hline
\end{tabular}


TABLE II. - Continued.

(g) Electron temperature $=\mathbf{8 . 0}$

\begin{tabular}{|c|l|l|l|l|l|l|l|}
\hline Term & $\begin{array}{l}\log n_{e} \\
10.50\end{array}$ & $\begin{array}{l}\log n_{e} \\
10.75\end{array}$ & $\begin{array}{l}\log n_{e} \\
11.00\end{array}$ & $\begin{array}{l}\log n_{e} \\
11.25\end{array}$ & $\begin{array}{l}\log n_{e} \\
11.50\end{array}$ & $\begin{array}{l}\log n_{e} \\
11.75\end{array}$ & $\begin{array}{l}\log n_{e} \\
12.00\end{array}$ \\
\hline${ }^{7} S_{3}$ & $1.00 e-0$ & $1.00 e-0$ & $1.00 e-0$ & $1.00 e-0$ & $9.99 e-1$ & $9.98 e-1$ & $9.97 e-1$ \\
${ }^{5} P_{2}$ & $6.96 e-6$ & $1.24 e-5$ & $2.20 e-5$ & $3.91 e-5$ & $6.95 e-5$ & $1.24 e-4$ & $2.19 e-4$ \\
${ }^{5} P_{3}$ & $9.62 e-6$ & $1.71 e-5$ & 3.04 & $5.41 e-5$ & $9.61 e-5$ & $1.71 e-4$ & 3.03 \\
$z^{7} P_{2}$ & $1.13 e-5$ & $2.01 e-5$ & 3.57 & $6.35 e-5$ & $1.13 e-4$ & $2.01 e-4$ & 3.56 \\
$z^{7} P_{3}$ & $1.52 e-5$ & $2.70 e-5$ & 4.80 & $8.54 e-5$ & $1.52 e-4$ & $2.70 e-4$ & 4.79 \\
$z^{7} P_{4}$ & $1.82 e-5$ & $3.24 e-5$ & 5.76 & $1.02 e-4$ & $1.82 e-4$ & $3.23 e-4$ & 5.74 \\
$y^{7} P_{2}$ & $4.96 e-6$ & $8.82 e-6$ & 1.57 & $2.79 e-5$ & $4.96 e-5$ & $8.81 e-5$ & 1.56 \\
$y^{7} P_{3}$ & $6.74 e-6$ & $1.20 e-5$ & 2.13 & $3.79 e-5$ & $6.73 e-5$ & $1.20 e-4$ & 2.12 \\
$y^{7} P_{4}$ & $8.23 e-6$ & $1.46 e-5$ & 2.60 & $4.63 e-5$ & $8.23 e-5$ & $1.46 e-4$ & 2.60 \\
${ }^{7} D_{2}$ & $5.06 e-6$ & $8.99 e-6$ & 1.60 & $2.84 e-5$ & $5.05 e-5$ & $8.98 e-5$ & 1.59 \\
${ }^{7}{ }_{D_{3}}$ & $6.63 e-6$ & $1.18 e-5$ & 2.10 & $3.72 e-5$ & $6.62 e-5$ & $1.18 e-4$ & 2.09 \\
\hline
\end{tabular}

(h) Electron temperature $=9.0$

\begin{tabular}{|c|c|c|c|c|c|c|c|}
\hline${ }^{7} S_{2}$ & $1.00 \mathrm{e}-0$ & $1.00 \mathrm{e}-0$ & $1.00 \mathrm{e}-0$ & $9.99 e-1$ & $9.99 \mathrm{e}-1$ & $9.98 \mathrm{e}-1$ & $9.97 e-1$ \\
\hline & $7.46 e-6$ & $1.33 e-5$ & $2.36 e-5$ & $4.19 e-5$ & $7.45 e-5$ & $1.32 \mathrm{e}-4$ & $2.35 e-4$ \\
\hline & $1.03 e-5$ & $1.83 e-5$ & 3.26 & $5.80 e-5$ & $1.03 e-4$ & $1.83 e-4$ & 3.25 \\
\hline$z^{7} P_{2}$ & $1.20 e-5$ & $2.14 \mathrm{e}-5$ & 3.81 & $6.77 e-5$ & $1.20 \mathrm{e}-4$ & $2.14 e-4$ & 3.79 \\
\hline & $1.62 e-5$ & $2.88 \mathrm{e}-5$ & 5.12 & $9.10 e-5$ & $1.62 \mathrm{e}-4$ & $2.87 e-4$ & 5.10 \\
\hline & $1.94 \mathrm{e}-5$ & $3.46 e-5$ & 6.14 & $1.09 e-4$ & $1.94 \mathrm{e}-4$ & $3.45 e-4$ & 6.12 \\
\hline$y^{7} P_{2}$ & $5.34 \mathrm{e}-6$ & $9.49 e-6$ & 1.69 & $3.00 e-5$ & $5.33 e-5$ & $9.48 e-5$ & 1.68 \\
\hline$y^{7} P_{3}$ & $7.25 e-6$ & $1.29 \mathrm{e}-5$ & 2.29 & $4.08 \mathrm{e}-5$ & $7.24 e-5$ & $1.29 \mathrm{e}-4$ & 2.28 \\
\hline$y^{7} P_{4}$ & $8.87 e-6$ & $1.58 \mathrm{e}-5$ & 2.80 & $4.98 \mathrm{e}-5$ & $8.86 e-5$ & $1.57 \mathrm{e}-4$ & 2.80 \\
\hline & $5.44 e-6$ & $9.68 \mathrm{e}-6$ & 1.72 & $3.06 e-5$ & $5.44 e-5$ & $9.66 e-5$ & 1.72 \\
\hline $\mathrm{D}_{3}$ & $7.74 e-6$ & $1.27 e-5$ & $2.26 \downarrow$ & $4.01 e-5$ & $7.13 e-5$ & $1.27 e-4$ & $2.25 \downarrow$ \\
\hline
\end{tabular}


TABLE II. - Concluded.

(i) Electron temperature $=10.0$

\begin{tabular}{|c|c|c|c|c|c|c|c|}
\hline Term & $\begin{array}{l}\log n_{e} \\
10.50\end{array}$ & $\begin{array}{l}\log n_{e} \\
10.75\end{array}$ & $\begin{array}{l}\log n_{e} \\
11.00\end{array}$ & $\begin{array}{l}\log n_{e} \\
11.25 \\
\end{array}$ & $\begin{array}{l}\log n_{e} \\
11.50\end{array}$ & $\begin{array}{l}\log n_{e} \\
11.75\end{array}$ & $\begin{array}{l}\log n_{e} \\
12.00\end{array}$ \\
\hline & $1.00 \mathrm{e}-0$ & $1.00 \mathrm{e}-0$ & $1.00 \mathrm{e}-0$ & $9.99 e-1$ & $9.99 \mathrm{e}-1$ & $9.98 \mathrm{e}-1$ & 19.97e \\
\hline & $7.90 e-6$ & $1.40 e_{-5}$ & $2.50 e_{-5}^{5}$ & $4.44 e-5$ & $7.89 e-5$ & $1.40 \mathrm{e}-4$ & $2.49 \mathrm{e}-4$ \\
\hline & $1.09 e-5$ & 1.94 & 3.45 & $6.14 e-5$ & $1.09 \mathrm{e}-4$ & 1.94 & 3.44 \\
\hline$z^{7} P_{2}$ & $1.27 e-5$ & 2.26 & 4.01 & $7.14 e-5$ & $1.27 \mathrm{e}-4$ & 2.25 & 4.00 \\
\hline & $1.71 \mathrm{e}-5$ & 3.04 & 5.40 & $9.60 e-5$ & $1.71 \mathrm{e}-4$ & 3.03 & 5.38 \\
\hline & $2.05 e-5$ & 3.65 & 6.48 & $1.15 e-4$ & $2.05 e-4$ & 3.64 & 6.46 \\
\hline & $5.67 e-6$ & 1.01 & 1.79 & $3.19 \mathrm{e}-5$ & $5.67 e-5$ & 1.01 & 1.79 \\
\hline$y^{7} P_{3}$ & $7.71 e-6$ & 1.37 & 2.44 & $4.33 e-5$ & $7.70 e-5$ & 1.37 & 2.43 \\
\hline$y^{7} P_{4}$ & $9.43 e-6$ & 1.68 & 2.98 & $5.30 e-5$ & $9.42 \mathrm{e}-5$ & 1.67 & 2.97 \\
\hline & $5.78 \mathrm{e}-6$ & 1.03 & 1.83 & $3.25 \mathrm{e}-5$ & $5.78 e-5$ & 1.03 & 1.82 \\
\hline${ }^{7} D_{3}$ & $7.59 e-6$ & $1.35 \downarrow$ & 2.40 & $4.26 e-5$ & $7.58 e-5$ & $1.35 \downarrow$ & $2.39 \downarrow$ \\
\hline
\end{tabular}

(j) Electron temperature $=11.0$

\begin{tabular}{|c|c|c|c|c|c|c|c|}
\hline$S_{2}$ & $1.00 e-0$ & $1.00 \mathrm{e}-0$ & $1.00 \mathrm{e}-0$ & $9.99 e-1$ & $9.99 \mathrm{e}-1$ & $9.98 \mathrm{e}-1$ & $9.96 \mathrm{e}-1$ \\
\hline & $8.29 e-6$ & $1.47 e-5$ & $2.62 e-5$ & $4.66 e-5$ & $8.28 e-5$ & $1.47 \mathrm{e}-4$ & $2.61 e-4$ \\
\hline & $1.15 e-5$ & 2.04 & 3.62 & $6.44 e-5$ & $1.14 \mathrm{e}-4$ & 2.04 & 3.61 \\
\hline$z^{7} P_{2}$ & $1.33 e-5$ & 2.36 & 4.20 & $7.46 e-5$ & $1.33 e-4$ & 2.36 & 4.18 \\
\hline & $1.79 e-5$ & 3.18 & 5.65 & $1.00 \mathrm{e}-4$ & $1.78 \mathrm{e}-4$ & 3.17 & 5.63 \\
\hline & $2.15 e-5$ & 3.82 & 6.78 & $1.21 e-4$ & $2.14 e-4$ & 3.81 & 6.76 \\
\hline & $5.97 e-6$ & 1.06 & 1.89 & $3.36 \mathrm{e}-5$ & $5.96 \mathrm{e}-5$ & 1.06 & 1.88 \\
\hline & $8.11 e-6$ & 1.44 & 2.56 & $4.56 e-5$ & $8.10 e-5$ & 1.44 & 2.56 \\
\hline$y^{7} p_{4}$ & $9.93 e-6$ & 1.77 & 3.14 & $5.58 \mathrm{e}-5$ & $9.92 e-5$ & 1.76 & 3.13 \\
\hline & $6.08 e-6$ & 1.08 & 1.92 & $3.42 e-5$ & $6.08 e-5$ & 1.08 & 1.92 \\
\hline 7 & $7.99 e-6$ & $1.42 \downarrow$ & $2.52 \downarrow$ & $4.49 e-5$ & $7.98 e-5$ & $1.42 \downarrow$ & $2.52 \downarrow$ \\
\hline
\end{tabular}


TABLE III. - CALCULATED AND MEASURED SCREEN GRID SPUTTERING RATESa

\begin{tabular}{|c|c|c|c|c|c|c|c|c|}
\hline Date & Location & $\begin{array}{c}\mathrm{Size} \\
\mathrm{cm}\end{array}$ & $\begin{array}{l}\text { Duration, } \\
\text { hr }\end{array}$ & $\begin{array}{c}\text { Beam } \\
\text { current, } \\
\text { A }\end{array}$ & $\begin{array}{c}\text { Discharge } \\
\text { voltage, } \\
v\end{array}$ & $\begin{array}{c}\text { Measured } \\
\text { screen } \\
\text { erosion, } \\
\text { A/hr }\end{array}$ & $\begin{array}{c}\text { Uncertainty, } \\
A / h r\end{array}$ & $\begin{array}{c}\text { Calculated } \\
\text { screen grid } \\
\text { erosion, } \\
\AA / h r\end{array}$ \\
\hline $\begin{array}{l}1974 \\
1976 \\
1977 \\
1971 \\
1981 \\
1983\end{array}$ & $\begin{array}{l}\text { Hughes } \\
\text { XEOS } \\
\text { Hughes }\end{array}$ & $\downarrow$ & $\begin{array}{r}10000 \\
4 \quad 165 \\
590 \\
\\
937 \\
4263 \\
9489\end{array}$ & $\begin{array}{l}1.4 \\
2.0 \\
2.0 \\
2.0 \\
1.96 \\
.078\end{array}$ & $\begin{array}{l}37.0 \\
36.1 \\
36 \\
32 \\
32 \\
36.6\end{array}$ & $\begin{array}{c}350 \\
312 \\
350 \\
80-100 \\
64 \\
-\cdots--\end{array}$ & $\begin{array}{l}-\cdot \\
-. \\
50 \\
20 \\
- \\
\cdots\end{array}$ & $\begin{array}{r}295 \\
295 \\
80 \\
80 \\
79\end{array}$ \\
\hline
\end{tabular}

as compiled by reference 2 .

bReference 62 . 


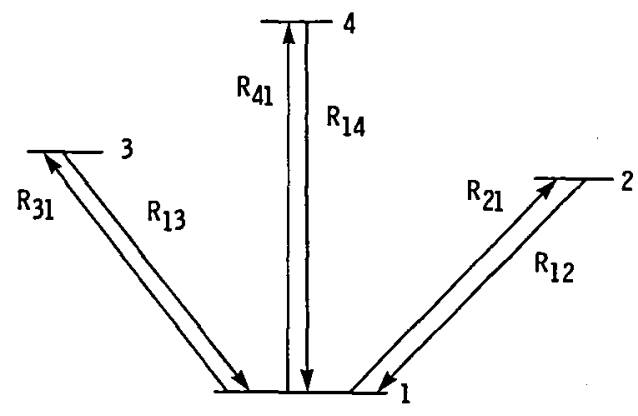

Figure 1. - A Grotrian diagram for a hypothetical 4 level system, showing the resonance transitions. Rate constants for the transitions are shown as well. 


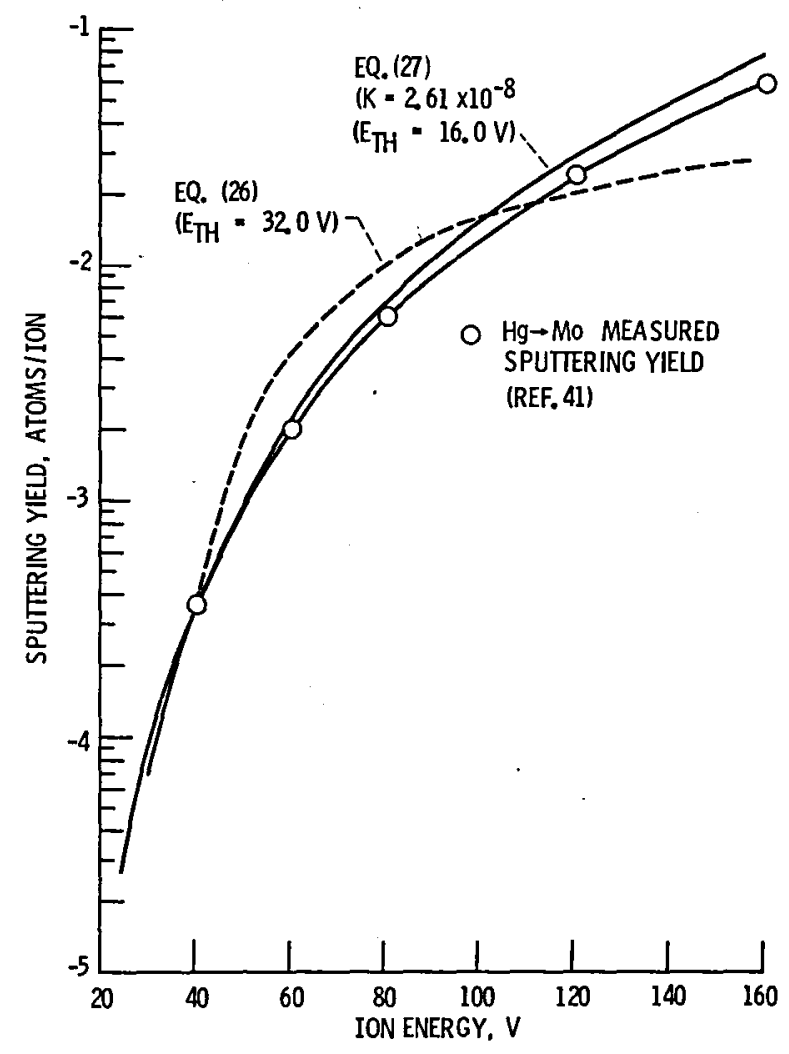

Figure 2 - Comparison of $\mathrm{Hg} \rightarrow \mathrm{Mo}$ calculated and measured sputtering yields as a function of ion energy. 


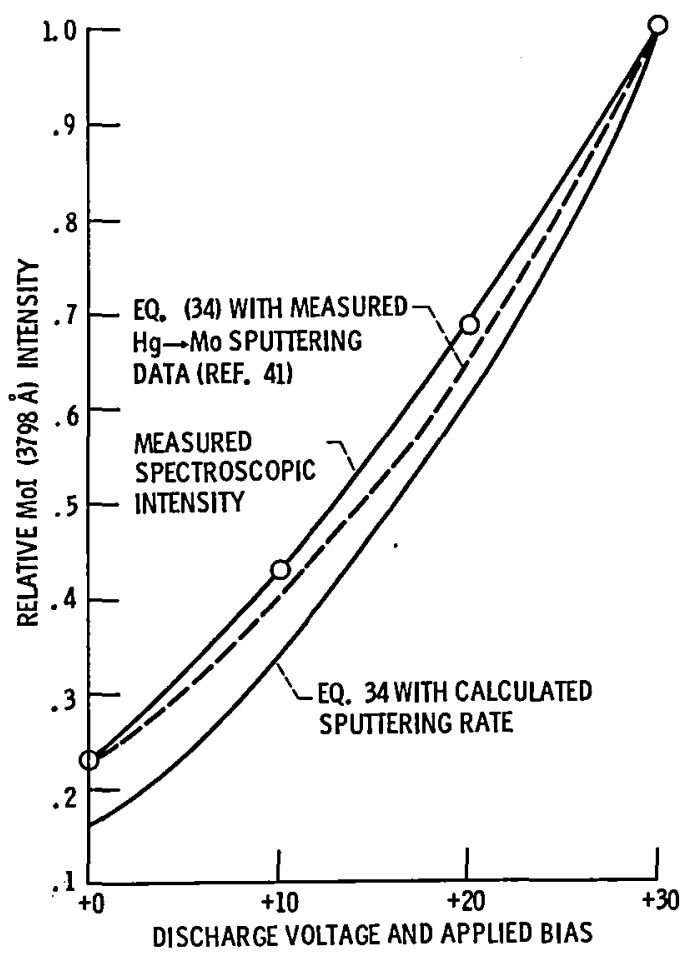

Figure 3. - Relative MoI intensity as a function of applied bias to the screen grid $\mathrm{U}_{B}=20 \mathrm{~A}, \Delta \mathrm{V}_{\mathrm{I}}=50.0 \mathrm{~V}$. 


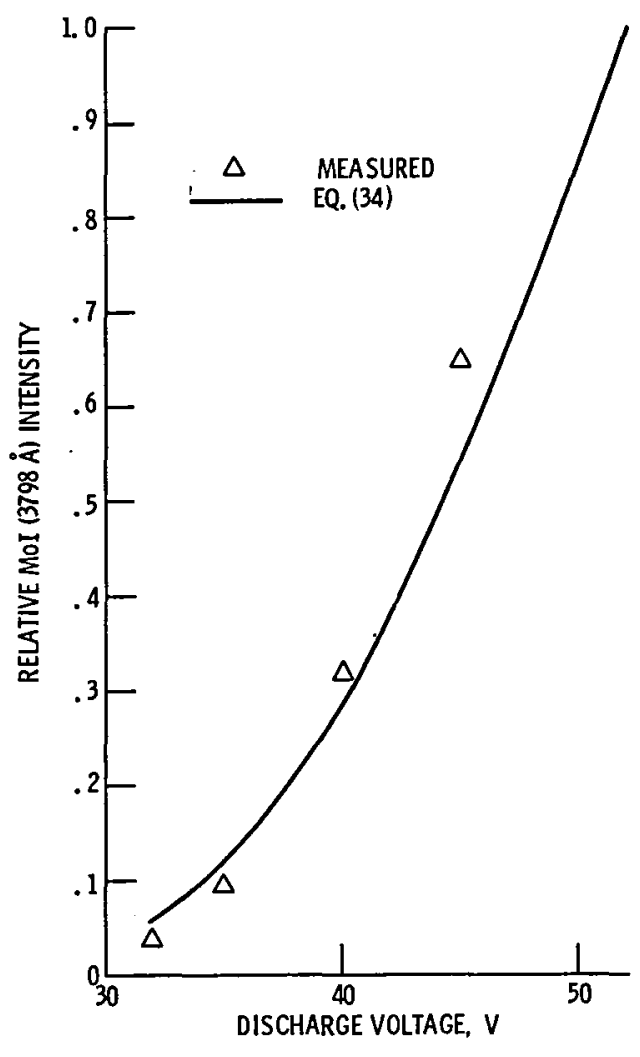

Figure 4. - Relative MoI intensity as a function

of discharge voltage $\left(30 \mathrm{~cm}\right.$ thruster, $\left.J_{B}=3.0 \mathrm{~A}\right)$. 


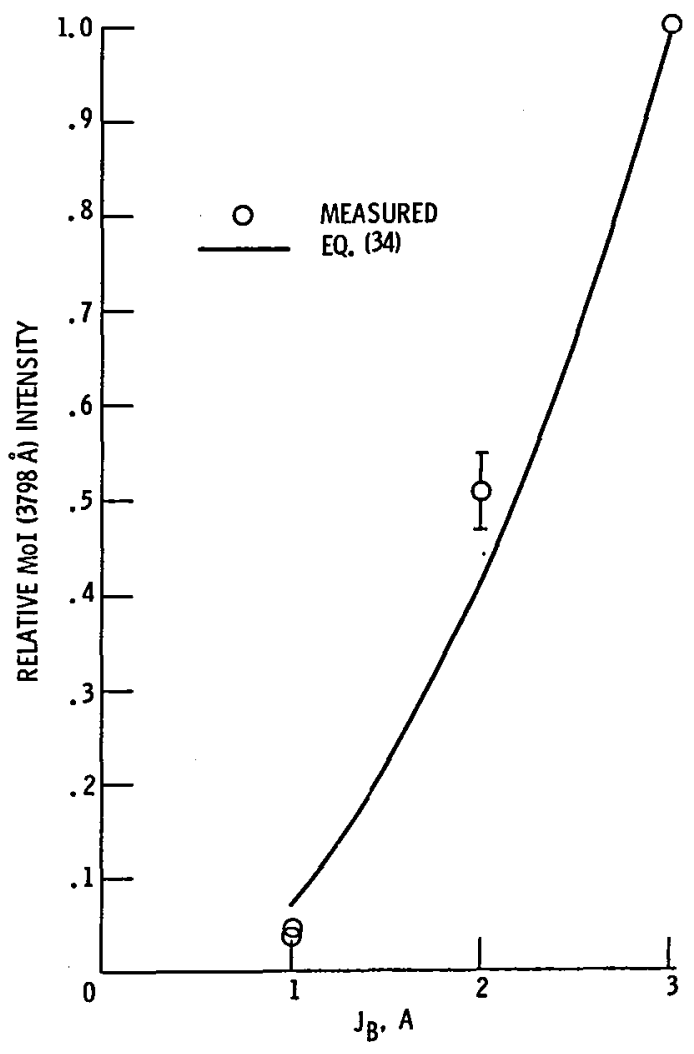

Figure 5. - Relative MoI intensity as a function of beam current, $J_{B}(30-\mathrm{cm}$ thruster, $\Delta V=50 \mathrm{~V})$. 


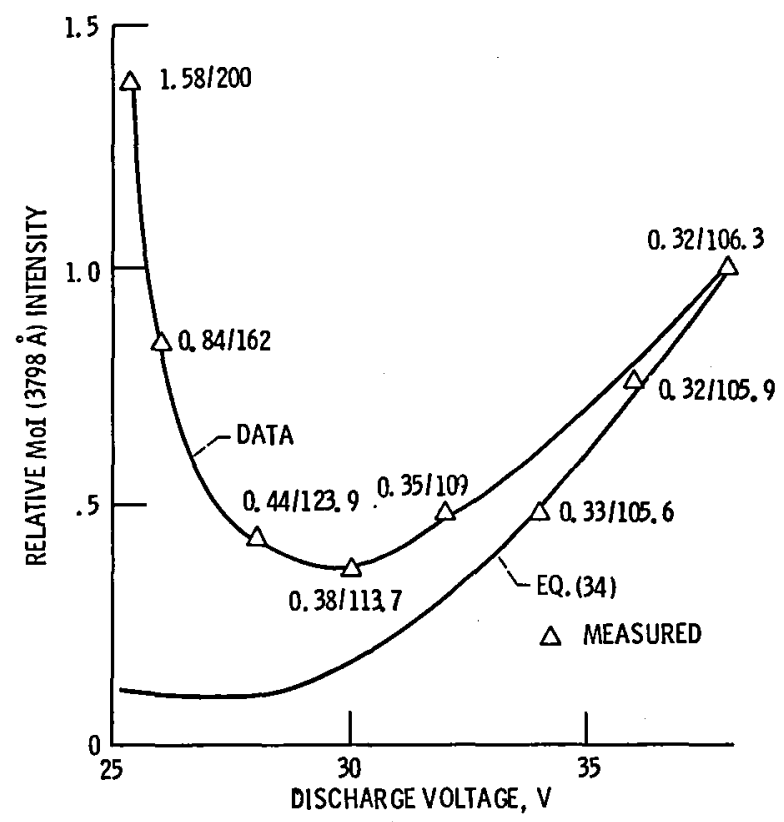

Figure 6. - Relative MoI intensity as a function of discharge voltage $\left(8-\mathrm{cm}\right.$ thruster, discharga current 3.0 A. ) $\frac{\mathrm{XX}}{\mathrm{XXX}}$ designates accelerator to beam current ratio in $\mathrm{mA}$. 


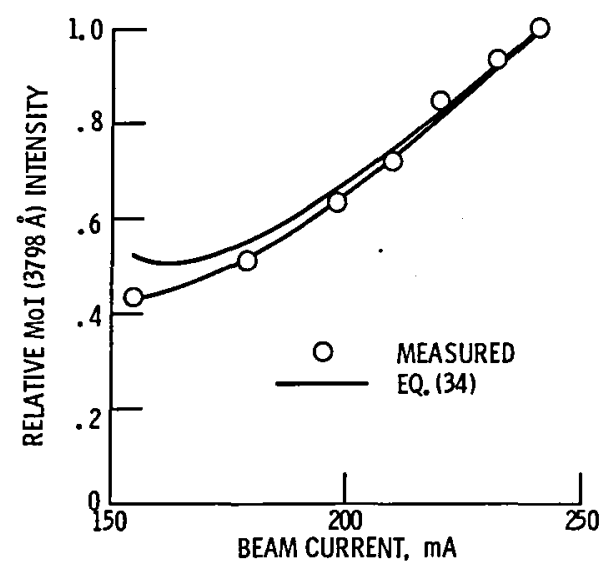

Figure 7. - Relative MoI intensity as function of beam current (8-cm thruster, $\Delta V_{1}=26.0 \mathrm{~V}$ ). 
GROTRIAN DIAGRAM OF MOLYBDENUM

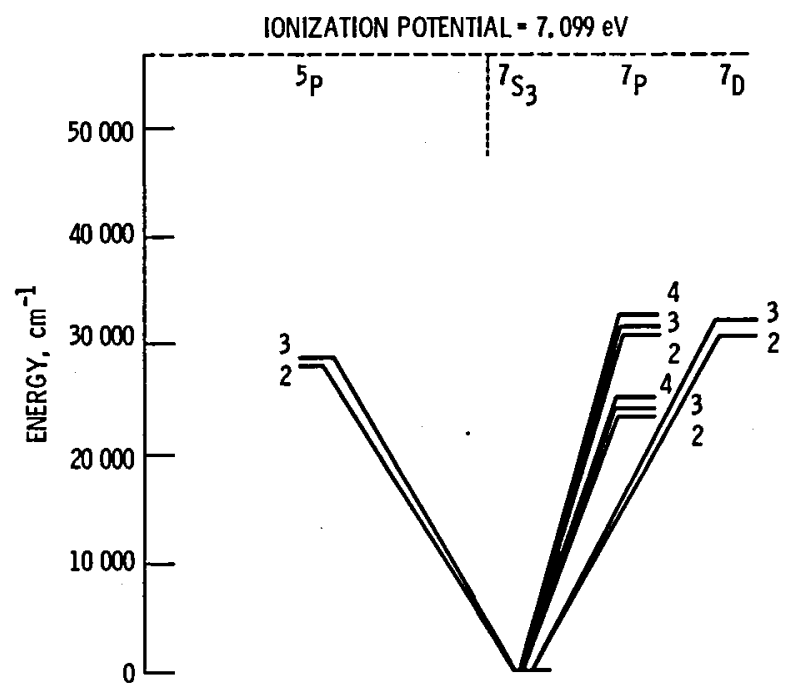

Figure Al. - Grotrian diagram of molybdenum for the system under consideration, showing the ten resonance transitions for the ten excited states chosen for use in the model. Adapted from reference 11 . 


\begin{tabular}{|c|c|c|}
\hline $\begin{array}{ll}\text { 1. Report No. } & \text { NASA TM-87103 } \\
\text { AIAA-85-2011 }\end{array}$ & 2. Government Accession No. & 3. Recipient's Catalog No. \\
\hline \multirow{3}{*}{\multicolumn{2}{|c|}{$\begin{array}{l}\text { 4. Title and Subtitle } \\
\text { Rapid Evaluation of Ion Thruster Lifetime Using } \\
\text { Optical Emission Spectroscopy }\end{array}$}} & 5. Report Date \\
\hline & & \\
\hline & & \\
\hline \multirow{3}{*}{\multicolumn{2}{|c|}{$\begin{array}{l}\text { 7. Author(s) } \\
\text { Brian A. Rock, Maris A. Mantenieks, and } \\
\text { Michael L. Parsons }\end{array}$}} & 8. Performing Organization Report No. \\
\hline & & $E-2700$ \\
\hline & & 10. Work Unit No. \\
\hline \multirow{3}{*}{\multicolumn{2}{|c|}{$\begin{array}{l}\text { 9. Performing Organization Name and Address } \\
\text { National Aeronautics and Space Administration } \\
\text { Lewis Research Center } \\
\text { Cleveland, Ohio } 44735\end{array}$}} & \\
\hline & & 11. Contract or Grant No. \\
\hline & & \\
\hline \multirow{2}{*}{\multicolumn{2}{|c|}{$\begin{array}{l}\text { 12. Sponsoring Agency Name and Address } \\
\text { Nationa } 1 \text { Aeronautics and Space Administration } \\
\text { Washington, D.C. } 20546\end{array}$}} & Technical Memorandum \\
\hline & & 14. Sponsoring Agency Code \\
\hline \multirow{2}{*}{\multicolumn{3}{|c|}{$\begin{array}{l}\text { 15. Supplementary Notes } \\
\text { Brian A. Rock and Michael L. Parsons, both of Arizona State University, Tempe, } \\
\text { Arizona; Maris A. Mantenieks, NASA Lewis Research Center. Prepared for the 18th } \\
\text { International Electric Propulsion Conference, cosponsored by the AIAA, JSASS, } \\
\text { and DGLR, Alexandria, Virginia, September 30-0ctober 2, 1985. }\end{array}$}} \\
\hline & & \\
\hline \multicolumn{3}{|c|}{ 16. Abstract } \\
\hline \multicolumn{3}{|c|}{$\begin{array}{l}\text { A major life-limiting phenomenon of electric thrusters is the sputter erosion of } \\
\text { discharge chamber components. Thrusters for space propulsion are required to } \\
\text { operate for extended periods of time, usually in excess of } 10 \text { o00 hr. Lengthy } \\
\text { and very costly life-tests in high-vacuum facilities have been required in the } \\
\text { past to determine the erosion rates of thruster components. It is, therefore, } \\
\text { highly desirable to develop alternative methods for determining erosion rates } \\
\text { which can be performed in relatively short periods of time at considerably lower } \\
\text { costs. This paper presents an attempt to relate optical emission intensity from } \\
\text { an ion bombarded surface (screen grid) to the sputtering rate of that surface. } \\
\text { The model used a kinetic steady-state (KSS) approach, balancing the rates of } \\
\text { population and depopulation of ten low-lying excited states of the sputtered } \\
\text { molybdenum atom (MoI) with those of the ground state to relate the spectral } \\
\text { intensities of the various transitions of the MoI to the population densities. } \\
\text { Once this is accomplished, the population density can be related to the sputter- } \\
\text { ing rate of the target. Radiative and collisional modes of excitation and decay } \\
\text { were considered. Since actual data has not been published for Moi excitation } \\
\text { rate and decay constants, semiempirical equations were used. The calculated } \\
\text { sputtering rate and intensity was compared to the measured intensity and sput- } \\
\text { tering rates of the 8- and } 30-c m \text { ion thrusters. }\end{array}$} \\
\hline
\end{tabular}

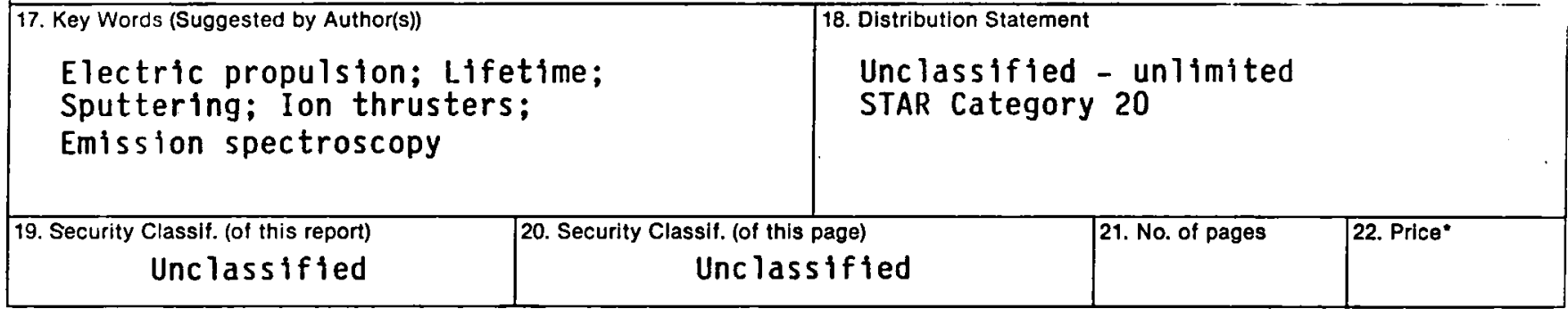

"For sale by the National Technical Information Service, Springfield, Virginia 22161 
End of Document 